\title{
Working Models of Attachment: Implications for Explanation, Emotion, and Behavior
}

\author{
Nancy L. Collins \\ State University of New York at Buffalo
}

\begin{abstract}
Two studies examined attachment style differences in social perception. In Study 1, participants wrote open-ended explanations for hypothetical relationship events and described how they would feel and behave in response to each event. Compared with secure participants, preoccupied participants explained events in more negative ways; they also reported more emotional distress and behaviors that were likely to lead to conflict. Avoidant participants also provided negative explanations, but did not report emotional distress. Path analysis indicated that attachment style differences in behavior were mediated by explanation patterns and emotional distress. Study 2 was designed to replicate Study 1 and test the relative importance of attachment style and relationship quality to predicting each outcome. Results indicated that both variables were significant predictors of explanations, but only attachment style predicted emotional responses. These findings are consistent with the idea that adults with different working models of attachment are predisposed to think, feel, and behave differently in their relationships.
\end{abstract}

\begin{abstract}
Every situation we meet with in life is constructed in terms of the representational models we have of the world about us and of ourselves. Information reaching us through our sense organs is selected and interpreted in terms of those models, its significance for us and for those we care for is evaluated in terms of them, and plans of action conceived and executed with those models in mind. On how we interpret and evaluate each situation, moreover, turns also how we feel. (Bowlby, 1980, p. 229)
\end{abstract}

As individuals enter new relationships, they carry with them a history of personal and interpersonal experiences that shape how they think and feel about their relationships and how they behave in those relationships. Recently, attachment theory has been used as a framework for understanding the specific processes through which close relationships in adulthood are influenced by each partner's personal and interpersonal history. Central to this approach is the notion of working models of self and others (Bartholomew \& Horowitz, 1991; Collins \& Read, 1990; Main, Kaplan, \& Cassidy, 1985). According to attach-

This article is based on a doctoral dissertation submitted to the University of Southern California. Special thanks to committee members Steve Read, Norman Miller, Shelley Duval, David Walsh, and Margaret McLaughlin for their valuable insights and suggestions. I am deeply indebted to David Jones, Heidi Lincer, and Michael Purvis for serving as skillful coders for this project. Finally, I wish to thank Steve Read and Sarah Ullman for helpful comments on previous versions of this article.

Funding for this project was provided by a research award from the Science Directorate of the American Psychological Association. The author was supported by a fellowship from the John Randolf and Dora Haynes Foundation during the conduct of this research, and by National Institute of Mental Health postdoctoral fellowship MH15750 during the preparation of this article.

Correspondence concerning this article should be addressed to Nancy L. Collins, Department of Psychology, State University of New York, Buffalo, New York 14260-4110. Electronic mail may be sent via Internet to ncollins@acsu.buflalo.edu. ment theory, these cognitive, representational models begin to develop in the context of parent-child interactions and are then carried forward into new relationships, where they guide how individuals manage their relationships and how they construe their social world (Collins \& Read, 1994; Shaver, Collins, \& Clark, 1996). However, the specific processes through which these models operate remain poorly understood. The purpose of the current research was to explore these processes by examining attachment style differences in the perception of social events. Specifically, two studies tested the hypothesis that adults with different working models of attachment would interpret and explain relationship events in ways consistent with their existing models of self and others. An additional aim was to examine a broader model of social functioning that included cognition as well as affect and behavior. A model linking attachment style and explanation patterns to emotional responses and behavioral intentions was proposed and tested.

\section{Working Models of Attachment}

Bowlby $(1973,1980,1982)$ used the term working models to describe the internal representations that individuals develop of the world and of significant people within it, including the self. These representations take root in infancy and early childhood and are presumed to be largely determined by the caregiver's emotional availability and responsiveness to the child's needs (Bretherton, 1985; Sroufe \& Waters, 1977). According to Main et al. (1985), a child's early working models are composed of schemata that represent his or her attempts to gain comfort and security. Over time, these specific experiences become abstracted into more generalized beliefs and expectations about the warmth and responsiveness of others and about the worthiness of the self. Once developed, these beliefs can be used to predict and interpret the behavior of others and to act in new situations without evaluating each one from the beginning.

Although each child's experiences, and hence working 
models, are unique, certain regularities have been observed in the nature and quality of infant-caretaker relations. On the basis of structured laboratory procedures and home observations, three distinct behavioral patterns or styles of infant attachment have been identified: secure, avoidant, and anxious-ambivalent (Ainsworth, Blehar, Waters, \& Wall, 1978). These styles are closely associated with differences in caretaker warmth and responsiveness, and are thought to reflect differences in the psychological organization of the attachment system ( for reviews of this literature, see Bretherton, 1985; Rothbard \& Shaver, 1994). Indeed, Main et al. (1985) suggested that the three attachment styles are best understood as "terms referring to particular types of internal working models of relationships, models that direct not only feelings and behavior but also attention, memory, and cognition"'(p.67).

Of course, representations of self and others continue to evolve as individuals encounter new relationships throughout their lives. Nevertheless, attachment theory suggests that cognitive models that begin their development early in one's personal history are likely to remain influential (Collins \& Read, 1994). On the basis of these ideas, social and clinical psychologists have begun to explore attachment theory as a framework for understanding social functioning in adulthood, particularly in the context of adult romantic relationships (for reviews, see Bartholomew, 1993; Shaver \& Hazan, 1993). Although the research is still in its early stages, three broad conclusions can be drawn from the current literature on adult attachment. First, the styles of attachment observed in children appear useful for describing individual differences in adult styles of relating. Although there are a number of unresolved conceptual and measurement issues, there is growing consensus on the prototypic features of each style (Collins \& Read, 1990; Feeney, Noller, \& Hanrahan, 1994; Griffin \& Bartholomew, 1994; Hazan \& Shaver, 1987, 1993). Secure adults describe themselves as comfortable with closeness and intimacy, as willing to rely on others when needed, and as confident that they are loved and valued. In contrast, avoidant adults report being very uncomfortable getting close to and depending on others, and they tend to be unconcerned about whether others will accept or reject them. Finally, preoccupied adults have a strong desire for close relationships, although they are unsure about whether they can depend on others and tend to worry a great deal about being rejected and abandoned. These patterns, measured through selfreport and interview methodologies, appear fairly stable over time (Collins \& Read, 1990; Kirkpatrick \& Davis, 1994; Scharfe \& Bartholomew, 1994) and are associated with memories of relationships with parents in theoretically predictable ways (Collins \& Read, 1990; Hazan \& Shaver, 1987; Rothbard \& Shaver, 1994).

The second general conclusion that can be drawn from this literature is that differences in attachment style appear to be rooted in cognitive models of self and others (Collins \& Read, 1994). Support for this assumption is provided by several studies showing that adults with different attachment styles differ greatly in the way they view themselves and the social world (Carnelley \& Janoff-Bulman, 1992; Collins \& Read, 1990; Feeney \& Noller, 1990; Hazan \& Shaver, 1987). For example, Collins and Read (1990) found that people with a more secure attachment style were higher in self-worth, more confident in social situations, and more self-assertive. Secure adults also had more positive beliefs about the social world, viewing others as trustworthy, dependable, and altruistic. Those with a more preoccupied attachment style (which corresponds to the anxiousambivalent style in infants ) measured low in self-worth, social self-confidence, and assertiveness. Their view of human nature was also somewhat negative. They believed that people have little control over their lives, and they viewed others as complex and difficult to understand. Finally, avoidant adults tended to have positive views of themselves, indicated by high self-worth and assertiveness, although they viewed themselves as less confident in social situations and not interpersonally oriented. These adults also had largely negative views of human nature. Overall, they thought others were not trustworthy or dependable.

Evidence for attachment-style differences in working models is not limited to self-report studies. For example, using a response latency paradigm drawn from cognitive social psychology, Baldwin, Fehr, Keedian, and Seidel (1993) reasoned that individuals with different attachment styles should be more quick to recognize words that are congruent with their relational schemas. As predicted, when presented with words in a relational context, secure adults were quicker to recognize positive words, whereas avoidant adults responded more quickly to negative words. More recently, Mikulincer (1995) found that adolescents with different attachment styles differed not only in the content but also in the structure of their mental representations of their self. For example, compared with insecure adolescents, secure individuals were found to have more balanced, complex, and coherent self-structures.

The third general conclusion that can be drawn from the adult attachment literature is that adults with different attachment styles differ markedly in the quality of their love relationships (e.g., Brennan \& Shaver, 1992, 1995; Collins \& Read, 1990; Feeney \& Noller, 1990; Hazan \& Shaver, 1987; Kirkpatrick \& Davis, 1994; Levy \& Davis, 1988; Senchak \& Leonard, 1992; Simpson, 1990). Studies consistently find that adults with more secure working models report more positive relationship experiences than those with preoccupied or avoidant models. Secure individuals generally characterize their relationships as intimate, stable, and satisfying. In contrast, avoidant adults tend to report low levels of intimacy, commitment, and satisfaction, whereas preoccupied individuals report jealousy, conflict, and high levels of negative emotional experiences. Once again, it is noteworthy that these differences are not limited to self-report questionnaire studies. Recent studies have found differences using behavioral observations (e.g., Feeney, Noller, \& Callan, 1994; Kobak \& Hazan, 1991; Simpson, Rholes, \& Nelligan, 1992), content coding of relationship narratives (Feeney \& Noller, 1991), and even psychophysiological methods (Feeney \& Kirkpatrick, 1996).

Although the correlational nature of these studies does not permit us to draw firm conclusions about causality, the underlying assumption throughout this work is that attachment style directly contributes to relationship quality and does not merely reflect it. Individual differences in working models are assumed to play an important role by shaping partners' cognitive, emotional, and behavioral response patterns. However, the specific 


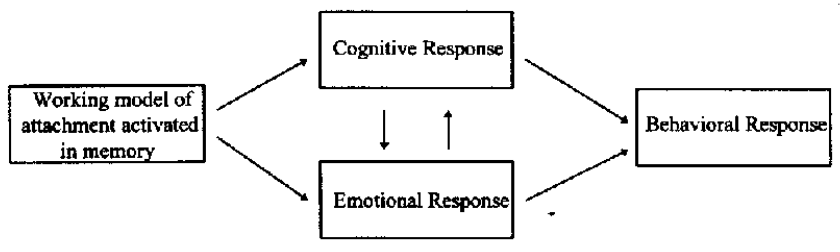

Figure 1. Hypothesized model linking working models of attachment to cognitive, emotional, and behavioral response patterns.

intra- and inter-personal mechanisms are only just beginning to be documented.

One way to begin exploring these mechanisms is to consider working models of attachment as part of a broader system of cognitive and motivational processes that enable people to make sense of their social experiences and to function in ways that serve their personal needs. On the basic of contemporary research and theory in personality and social psychology, Collins and Read (1994) have suggested a general framework for understanding how working models may function (see Figure 1). According to this framework, working models of attachment are highly accessible cognitive constructs that will be automatically activated in memory in response to attachment-relevant events. Once activated, they are predicted to have a direct impact on social information processing (including attention, memory, and inference) and on emotional response patterns. Rather than operate in isolation, cognitive and affective responses are also predicted to have reciprocal effects on each other. The outcome of these processes should then determine one's choice of behavioral strategies. Furthermore, it is not necessary to assume that people are consciously directing these processes, or even that they are aware of them. In fact, much of this system should operate "automatically," that is, spontaneously, with little effort and outside of awareness (Bargh, 1984).

In short, Collins and Read (1994) argued that the impact of working models on behavior in any given situation will be largely mediated by the subjective interpretation of the situation along with one's emotional response. This model is intended only to be a very general framework for exploring a number of more specific cognition-emotion-behavior linkages. The present study was the first step in a program of research designed to map out these links in greater detail. The primary purpose of these first studies was to explore the link between working models and cognitive response patterns. Cognitive models associated with attachment are presumed to guide the appraisal of social situations and to help individuals maintain a coherent world view and self-image (Bartholomew, 1990; Collins \& Read, 1990, 1994). Although there are many cognitive processes that should be shaped by working models ( see Collins \& Read, 1994), I began by focusing on one aspect of social cognition that has already been shown to have important implications for relationship functioning - attributional processes.

\section{Attachment Style Differences in Attributions and Explanations}

A large body of research points to the important role of attributions in relationship functioning (see Bradbury \& Fincham,
1990, for a review). Individuals in distressed relationships tend to make attributions that maximize the impact of their partner's negative behavior while discounting or minimizing the impact of positive behaviors. Moreover, several studies suggest that these patterns do not simply reflect relationship quality, but may actively contribute to it (Baucom \& Lester, 1986; Epstein, Pretzer, \& Fleming, 1987; Fincham \& Bradbury, 1987; Fletcher, Fincham, Cramer, \& Heron, 1987; Margolin \& Weiss, 1978). Although little is known about the origins of negative attributional patterns, several researchers have suggested that individual differences in beliefs and expectations may underlie such patterns (Baucom, Epstein, Sayers, \& Sher, 1989; Fincham, 1985; Fincham \& Bradbury, 1987, 1989; Fletcher \& Fitness, 1993). Working models associated with attachment may be one important source of these differences. This idea is compatible with a large body of research on the role of prior knowledge in social information processing and social judgment. Empirical work in social psychology clearly demonstrates that many aspects of social perception and inference are heavily influenced by top-down, theory-driven processes in which existing goals, schemas, and expectations shape the way people view new information ( for reviews, see Fiske \& Taylor, 1991; Markus \& Zajonc, 1985). Although most of this research involves thinking about strangers, these processes are increasingly being explored in the context of close relationships (e.g., Baldwin, 1992; Bugental, Blue, Cortez, \& Fleck, 1993; Fletcher \& Fincham, 1991; Fletcher \& Fitness, 1990; Holmes \& Rempel, 1989). Taken together, this work suggests that relationship partners are not simply passive recipients of environmental stimuli, but are active participants in the construction of their own reality.

Thus, like other cognitive representations, working models of attachment are likely to be important knowledge structures through which social events are filtered and understood. When attachment-relevant events occur, attachment models should be activated in memory automatically. Once activated, these models provide either well-learned and readily available explanations for many interpersonal events, or the social knowledge needed for the construction of new explanations "on-line." Furthermore, because adults with different attachment styles operate on the basis of very different models of themselves and the social world, they are likely to construe the same events in very different ways. Thus, individuals with different working models of attachment may be predisposed to interpret social events in ways that are consistent with their existing expectations and beliefs.

The primary purpose of the current research was to test the idea that working models of attachment bias and shape the explanation and attribution process. To accomplish this, openended explanations were gathered and content coded for the presence of attachment-relevant themes. It was predicted that explanations for attachment-relevant events would be shaped in specific ways that reflect underlying differences in models of self and others. For example, those with a secure attachment style should filter events through largely optimistic models. As a result, their explanations should reflect confidence that their partner is trustworthy and caring, and should minimize the importance of the event for issues of relationship stability. In contrast, preoccupied and avoidant individuals should be more likely to explain events in ways that suggest their partner's lack of re- 
sponsiveness and negative motivation and to interpret events as having negative implications for the security of their relationship. In addition, because of their negative models of themselves, preoccupied individuals may be more likely to see themselves as the cause of their partner's behavior and to provide explanations that reflect a lack of self-worth and self-reliance.

To demonstrate that these differences are due to the activation of attachment-related models, rather than a more general perceptual bias, it was important to include events that were not expected to be influenced by attachment style. Although any relationship event could be relevant to attachment concerns, the goal was to identify events that were not as likely to activate attachment-relevant knowledge structures, or for which these structures, if activated, would provide less plausible explanations. For example, explaining why a partner was late for a date might be better understood by applying sex-role stereotypes (e.g., "she took too long getting dressed") or culturally shared beliefs (e.g., "he was picking up flowers"). Thus, it was predicted that all participants would be more likely to spontaneously mention attachment themes (e.g., trust, acceptance, and responsiveness) in response to attachment-relevant events than in response to attachment-irrelevant events. In addition, it was predicted that attachment-style differences in the content of explanations would be more evident in explanations given for attachment-relevant events.

\section{Attachment Style Differences in Emotion and Behavior}

A secondary goal of this research was to provide an initial test of the general model presented in Figure 1, which includes not only cognition but also emotion and behavior. Emotional response patterns play a central role in attachment theory (see Shaver, Collins, \& Clark, 1996), and differences in attachment style are associated with variations in emotional expression and emotion regulation in both children (e.g., Sroufe \& Waters, 1977) and adults (Kobak \& Sceery, 1988).

Working models of attachment were predicted to have both direct and indirect associations with emotional response patterns. First, working models of attachment are expected to be heavily affect-laden, and this affect is likely to be automatically triggered when these models are activated (Collins \& Read, 1994), a process referred to as schema-triggered affect (Fiske \& Pavelchak, 1986; Markus \& Wurf, 1987). Strategies for acknowledging and managing emotional distress are also encoded in working models and should be automatically triggered as well (Shaver, Collins, \& Clark, 1996). Hence, adults with different attachment styles should differ in their emotional reactions to potentially negative relationship events. This relation is shown in Figure 1 as a direct path from attachment to emotional responses. It was predicted that individuals with more secure working models would be willing to acknowledge emotional distress, but would be unlikely to report extreme levels of distress. In contrast, preoccupied individuals were expected to report exaggerated levels of negative emotion, whereas those with more avoidant working models were expected to deny feelings of distress.

In addition to a direct association between working models and affect, it was predicted that there would be an indirect link, mediated through explanations. That is, an individual's emo- tional responses to an event should be due in part to his or her interpretation of the event. To the extent that a partner's behavior is viewed as selfishly motivated or as a sign that the relationship is in jeopardy, emotional distress should result. Thus, as shown in Figure 1, a path from explanation patterns to emotional distress was also expected. This link is consistent with a long history of theoretical and empirical work on the role of attributions and appraisals in emotional experience (e.g., Berscheid, 1983; Lazarus \& Folkman, 1984; Roseman, 1984; Weiner, 1982, 1985). (Although the model presented in Figure 1 also includes a direct link from emotional processes to cognitive processes, this relation was not investigated in the current study.)

The final step in the model was to examine behavioral response tendencies. Negative interpretations of a partner's behavior and negative emotional responses should lead to correspondent behaviors, which are likely to result in conflict and to contribute to relationship distress (Doherty, 1982; Fincham, Beach, \& Nelson, 1987; Fincham \& Bradbury, 1988; Fincham \& O'Leary, 1983). Thus, as shown in Figure 1, behavioral responses were expected to be directly predicted by the explanation given, along with the emotional response to the event. In summary, it was predicted that the relationship between attachment style and social behavior would be fully mediated through cognitive and emotional response patterns.

\section{Study 1}

The primary aim of Study 1 was to test the hypothesis that people's existing attachment-relevant beliefs about self and others bias the way they interpret and explain relationship experiences. Although the emphasis was on the content of free-response explanations, standard measures of attributional dimensions were also gathered. The secondary aim was to test the proposed multivariate model linking attachment style and explanation patterns to emotional responses and behavioral intentions. To examine the impact of general attachment-relevant models independent of any specific relationship, the sample included dating as well as nondating students, all of whom were asked to respond to the behavior of a fictional dating partner.

\section{Method}

\section{Overview}

Participants were asked to imagine themselves in a relationship with a fictional dating partner and were presented with a series of interpersonal events. Some of these events were attachment-relevant, some were attachment-irrelevant. For each event, participants (a) provided an openended written explanation for the partner's behavior, (b) rated a series of emotions describing how they would feel if that situation occurred, and (c) provided a written description of how they would respond to the partner. Participants also rated their explanation along a series of structured attribution dimensions, and completed a background questionnaire that included measures of attachment style. Open-ended explanations were then coded on dimensions derived from attachment theory, and behavioral responses were rated for the extent to which they would be likely to result in conflict. Bivariate relations between working models of attachment and explanation patterns, emotions, and behavioral intentions were then examined. Finally, the proposed multivariate model was tested through path analysis. 


\section{Participants}

Participants were 82 female and 53 male undergraduate students from the University of Southern California who participated in exchange for extra credit in their introductory psychology course. Participants ranged in age from 18 to 25 , with a mean age of 18.7. Fifty-five percent of participants were currently involved in a romantic relationship, $45 \%$ were not.

\section{Materials}

Participants completed three sets of materials: (a) a background questionnaire, (b) a relationship events questionnaire, and (c) an attributions questionnaire.

Background questionnaire. Participants were first asked several demographic questions and several questions about their current and past relationship experience. Individual differences in attachment style were then measured with a revised version of the Adult Attachment Scale (AAS) developed by Collins and Read (1990). ${ }^{1}$ This 18 -item scale contains three subscales (each with 6 items): (a) the close subscale measures the extent to which a person is comfortable with closeness and intimacy; (b) the depend subscale assesses the extent to which a person is comfortable depending on others and believes that people can be relied on when needed; and (c) the anxiety subscale measures the extent to which a person is worried about being rejected and abandoned by others. Participants were asked to respond to each item in terms of their general orientation toward close relationships.

The intercorrelations among the subscales were similar to those found in previous work: The close and depend subscales were fairly strongly correlated $(r=.53)$, and the anxiety subscale was moderately negatively correlated with the close $(r=-.34)$ and depend $(r=-.46)$ subscales. Cronbach's alphas for the close, depend, and anxiety subscales were $.77, .78$, and .85 , respectively. Consistent with previous work, there were no sex differences on any of the attachment dimensions.

The three dimensions measured by the AAS can be used in two different ways. First, the subscales can be used as continuous measures of the components that underlie differences in adult attachment patterns (comfort with closeness, comfort with depending on others, and fear of rejection ). Second, through cluster analysis, the subscales can be used to categorize people into discrete attachment styles (secure, avoidant, or preoccupied) according to their profile of scores along all three dimensions. For example, an individual with a secure attachment style is comfortable with closeness, believes that people are dependable, and is not anxious about being rejected or abandoned. Thus, the three dimensions can be used in combination to define discrete styles of attachment, but no single dimension corresponds to a single style. As argued elsewhere (Collins \& Read, 1990), an analysis of the continuous attachment dimensions can often provide a more precise understanding of attachment processes by specifying which component of one's working model is most critical to a given relation. This concern is especially relevant because specific attachment beliefs and concerns may be differentially reflected in people's explanations. Therefore, results will focus primarily on the continuous dimensions, although mean differences for attachment groups will be presented for selected outcomes.

Relationship events questionnaire. This booklet contained the primary stimulus materials and dependent measures. Each participant was presented with six potentially negative partner behaviors. ${ }^{2}$ Four of these were chosen, a priori, as attachment-relevant and two as attachmentirrelevant. Each attachment-relevant event was designed to tap into one of four central attachment themes: warmth and responsiveness, emotional availability when needed (safe haven), separation (proximity seeking), and use of one's partner as a secure base. The four events were, Your partner (a) didn't respond when you tried to cuddle, (b) didn't comfort you when you were feeling down, (c) wanted to spend an eve- ning by himself/ herself, and (d) left you standing alone at a party. The irrelevant events were chosen as irrelevant only in terms of their likelihood of activating attachment themes, not in terms of their potential for negative impact. ${ }^{3}$ The two events were: Your partner (a) borrowed money from you and didn't pay it back and (b) forgot your birthday. (It is important to note that the difference between the relevant and irrelevant events was expected to be relative, not absolute-any relationship event has the potential to be relevant to attachment concerns.) For all dependent variables, scores were averaged across the four attachment-relevant events and the two attachment-irrelevant events.

Each event was printed on a separate sheet of paper that participants received in counterbalanced order. Directly after each event description, participants were asked to provide an open-ended explanation for the partner's behavior. Specifically, they were asked, "Why do you think your partner behaved this way?" They were allowed to write an explanation of any length, but if they listed more than one explanation they were asked to circle the most likely one. (All analyses are based on the most likely explanation.) Following this task, participants rated the extent to which the event would be likely to lead to conflict if it occurred, on a scale from 1 (not at all) to 7 (very much).

Next, to assess affective reactions, participants were asked to take a moment to think about how they would feel if the event occurred that day. They then rated the extent to which they believed they would experience each of 13 emotions on a 7-point scale. These emotional reactions were expected to differentiate people with different attachment styles. A principal-components analysis with oblique rotation was conducted to reduce these items to a smaller set of underlying components.

\footnotetext{
${ }^{1}$ The revised scale includes the following changes. First, one item on the close subscale was replaced to improve reliability. The correlation between the revised scale and the original version was $r=.98$ in a sample of undergraduates $(N=295)$. Second, one item on the anxiety scale that was poorly worded has been replaced with a similar item. Finally, two items on the anxiety scale concerned with a strong desire to "merge" with a partner were replaced with two new items concerned with "ambivalence" about relationships. Ambivalence in this context refers to an approach-avoidance conflict between the desire to be close to others and the simultaneous fear that such closeness leaves one vulnerable to being hurt. The original two merge items were problematic because many respondents were confused about their meaning and because they tended to load weakly and inconsistently on factor analyses. As predicted, when factor analyzed, the two new items loaded strongly with the remaining four anxiety items. The correlation between the new anxiety subscale and the original version was $r=.86$ in a sample of undergraduates $(N=295)$.

${ }^{2}$ It is important to note that all six behaviors were potentially negative in impact. Positive events were not included because they are less likely in general to elicit active attributional processing (Weiner, 1985). Likewise, the marital literature finds that spontaneous attributions occur more often in response to negative partner behaviors in both distressed and nondistressed couples (Camper, Jacobson, Holzworth-Munroe, \& Schmaling, 1988; Holtzworth-Munroe \& Jacobson, 1985, 1988). In addition, as summarized by Bradbury and Fincham (1987), the occurrence of negative relationship events better predicts changes in day-today marital satisfaction than do positive events.

${ }^{3}$ The relative negativity of each event was determined by pretesting on a sample of undergraduate psychology students $(N=295)$ who rated the extent to which each of a list of events would cause them distress. On average, half of the events chosen in each category had been rated as moderately distressing (e.g., being left at a party, having a partner want to spend an evening alone, and a partner not paying back money that was borrowed), and half had been rated as highly distressing (e.g., not responding to a cuddle, not being comforted, and a partner forgetting one's birthday).
} 
Three factors emerged and were used as the basis for forming three composite indices: (a) Distress (angry, hurt, disappointed, unappreciated, sad, jealous, and unloved), (b) Nervousness (nervous, confused, and helpless), and (c) Unemotional (unemotional and indifferent). The Distress and Nervousness indices were strongly correlated with each other $(r=.75$ ), but were weakly related to the Unemotional index ( $r$ s $=-.24$ and -.20 , respectively).

Finally, behavioral intentions were measured by asking participants to describe in detail what they would say or do in response to the partner's behavior.

Attribution questionnaire. The final questionnaire presented participants with the six events again and asked them to rate the cause of the event along 10 standard attributional dimensions. These measures were presented in a separate booklet to avoid any potential influence on the content of free-response explanations. The 10 dimensions were based on previous research on attribution in the social psychology and marital literatures (e.g., Epstein et al., 1987; Fincham, 1985; Fincham \& Bradbury, 1987; Holtzworth-Munroe \& Jacobson, 1985; Passer, Kelley, \& Michela, 1978). Four items assessed the locus of the cause: Participants rated the extent to which the behavior was caused by something about (a) the partner, (b) the self (i.e., the participant), (c) outside circumstances, and (d) the relationship. Two items assessed the nature of the cause: Participants rated the extent to which the behavior was caused by something that is (e) stable (not likely to change) versus unstable, and ( $f$ ) global (i.e., affecting many areas of the relationship) versus specific (i.e., affecting only this area). Three items assessed attributions about the partner's motives and intentions: Participants rated the extent to which their partner's behavior was $(\mathrm{g})$ intended to have an impact on them (the participant), ( $h$ ) voluntary, and (i) intended to be negative. Finally, participants rated the extent to which the behavior was caused by (j) the partner's negative attitude toward them (the participant). Each dimension was rated on a 7-point scale, with higher scores representing greater assignment to that dimension.

Because several of these dimensions were conceptually related and were expected to be highly correlated, a principal-components analysis with oblique rotation was conducted and used as a basis for reducing these items. This analysis suggested that two sets of ratings should be combined. First, three ratings (caused by partner's negative attitude, behavior was intentional, and behavior was intended to be negative) were averaged to form an index of the extent to which the behavior was negatively motivated. The second index was an average of two ratings: the extent to which the cause of the event was perceived as stable and as global. The five remaining attribution dimensions did not form a clear set of factors and were therefore left as separate items.

\section{Procedure}

Experimental procedure. Participants completed materials in small groups of about 8 to 10 . They were given the background questionnaire first, which contained the attachment scale. Once they completed the questionnaire, participants were told that the purpose of the study was to understand how people explain events that occur in dating relationships. They were told that they would be responding to a series of hypothetical events for a fictional dating partner. Participants who were currently in a romantic relationship were instructed to think about a generalized partner and not their current partner. Participants then completed the relationship events and attribution questionnaires.

Coding open-ended explanations. Before coding, all open-ended explanations were transcribed onto index cards. Each explanation was then rated on nine a priori dimensions by two trained coders (one male and one female) who were graduate students in social psychology. The purpose of this coding was to assess themes that are likely to differentiate the explanations of people with different attachment styles. Eight of the nine dimensions assessed the extent to which the content was consistent with working models associated with attachment. The final coding dimension was a general evaluation of the extent to which the overall content of the explanation maximized or minimized the negative impact of the event. Each explanation was evaluated with respect to the following themes: (a) partner responsiveness, (b) participant's selfworth, (c) trust in partner, (d) confidence in partner's love, (e) confidence that partner is dependable, ( $f$ ) confidence that relationship is secure, (g) participant's self-reliance, (h) partner warmth and closeness, and (i) minimize-maximize negative impact of event. ${ }^{4}$

The coding for the first eight dimensions was done in two parts. First, each explanation was coded for whether it explicitly mentioned the attachment theme; this was simply coded as either "yes" or "no" for each theme. For example, consider the following explanations given by two participants in response to the first event ("your partner didn't respond to a cuddle"): (a) "My partner is losing interest in me" and (b) "He feels detached, doesn't want to be close to me." The first explanation received a "yes" check on the "partner love" theme and a "no" check on all others. The second received a "yes" check on the "partner warmthcloseness" theme and a "no" check on all others. An explanation could receive a check on more than one theme if applicable. High interrater agreement was achieved for this set of ratings. Agreement ranged from $90 \%$ to $97 \%$, with an average agreement of $94 \%$. Disagreements between raters were settled by $\mathrm{N}$. Collins.

This first coding simply measured whether an attachment theme was mentioned, not whether it was positive or negative. The second step was to rate the extent to which the explanation indicated or implied positive or negative information about each attachment theme. All eight attachment themes were rated on a 9-point scale ranging from -4 to +4 , with a neutral point in the middle. All scales were anchored, with the negative end reflecting low placement on that dimension (e.g., low self-worth or lack of trust). The final rating scale, which assessed the overall positive or negative implication of the explanation, was rated on a 9-point scale ranging from -4 (maximize the negative impact of the event) to +4 (minimize the negative impact of the event).

This second set of ratings required that each explanation be considered with reference to the specific event being explained and the range of possible explanations for that event. An example helps illustrate how the explanations were rated. Consider the following explanation that was given for the first event by a male participant: "She just had a bad day and wasn't in the mood to cuddle." The following are several alternatives given by other participants in this sample: (a) "She doesn't like me anymore," (b) "He's losing interest," (c) "He's mad at me and this is his way of punishing me." Given the available alternatives, the first participant's explanation reflects confidence that his partner cares about him, that his relationship is secure, and that his partner is not purposely rejecting closeness. Therefore, this explanation was given positive ratings on these dimensions. However, given the event being explained, this explanation provides no clear basis for making inferences about certain other dimensions, such as trust or self-reliance. Thus the neutral point on the scale was used when there was no basis for making inferences about a dimension or when the explanation reflected a neutral standing on a dimension.

Reliability coefficients for this second set of ratings ranged from .77 to .95 , indicating fairly strong agreement between raters on all dimensions. Reliability coefficients were also computed separately for the attachment-relevant and attachment-irrelevant events and were found to be highly comparable. However, for irrelevant events, four of the dimensions (self-worth, dependability, self-reliance, and warmth-closeness) were rated as "neutral" more than $85 \%$ of the time by one or both raters. This resulted in almost zero variance and very low reliability estimates.

\footnotetext{
${ }^{4}$ A more detailed description of the coding dimensions and procedures is available from N. L. Collins.
} 
As such, these four dimensions were not used to test hypotheses for the irrelevant events.

The average of the two coders' ratings was used in all analyses. An examination of the intercorrelations among the eight attachment themes revealed that most were only moderately or weakly associated, indicating that coders were able to successfully discriminate between the various dimensions ( the average intercorrelation was . 39 , and 20 of the 28 correlations were below .50). Nevertheless, three pairs of variables had substantial correlations: love and secure (.94), responsive and dependable $(.72)$, and self-worth and self-reliance ( .70$)$. Given the large degree of empirical as well as conceptual overlap, each pair was averaged into a single index.

Coding behavioral intentions. Participants' written descriptions of how they would respond to their partner were coded on two dimensions. First, drawing from prior research (Fincham, Beach, \& Nelson, 1987; Fincham \& O'Leary, 1983), behavioral descriptions were coded for the extent to which they would be punishing to their partner on a scale ranging from 1 (not at all) to 7 (extremely punishing). A punishing behavior was defined as one likely to result in negative consequences for the partner (e.g., hurt feelings, embarrassment, etc.). Next, each response was rated for the extent to which it would likely lead to conflict on a scale ranging from 1 (not at all likely) to 7 (extremely likely). Conflict was defined as any negative interaction or exchange between partners. Ratings were conducted by two trained, male coders, each of whom rated half the questionnaires. Interrater reliability was assessed by having each coder rate a random selection of the other's questionnaires, totaling $30 \%$ of the sample ( 240 responses overall). Interrater reliability was .91 for punishing and .88 for conflict, indicating strong interrater agreement on both dimensions. Because the correlation between the two dimensions was high for both coders (.84 and .79), the two ratings were averaged to provide an overall measure of the extent to which a behavior was punishing and likely to result in conflict.

\section{Results and Discussion}

First, correlational results examining the association between working models of attachment (comfort with closeness, comfort depending on others, and anxiety about being rejected or abandoned) and explanations, emotions, and behavioral intentions are presented. Next, participants were categorized into attachment styles (secure, avoidant, or preoccupied) on the basis of a cluster analysis of the three dimensions, and mean differences between these groups were examined for each outcome. Finally, the hypothesized multivariate model was tested using path analysis.

\section{Correlations Between Attachment Dimensions and All Outcome Variables}

Open-ended explanations: Explicit attachment themes. To test the prediction that attachment-relevant events would be more likely to elicit attachment content than irrelevant events, the likelihood of having at least one explicit attachment theme was compared for the two sets of events. As expected, participants were much more likely to spontaneously mention an attachment theme in response to an attachment event, $\chi^{2}(1, N=$ $135)=47.10, p<.001$. On average, $52 \%$ of explanations for attachment events contained at least one of the eight attachment themes, compared with only $22.5 \%$ for irrelevant events.

To determine if participants with different working models were more or less likely to mention explicit attachment themes, composite scores were computed to indicate the number of
Table 1

Correlations Between Attachment-Style Dimensions and Open-Ended Explanation Ratings

\begin{tabular}{|c|c|c|c|}
\hline \multirow[b]{2}{*}{ Explanation rating } & \multicolumn{3}{|c|}{ Attachment-style dimensions } \\
\hline & Close & Depend & Anxiety \\
\hline \multicolumn{4}{|l|}{ Attachment-relevant events } \\
\hline Love/security & $.252^{* *}$ & $.269^{* *}$ & $-.254^{* *}$ \\
\hline Responsive/dependable & $.288^{* * * *}$ & .161 & $-.211^{*}$ \\
\hline Self-worth/reliance & .157 & .140 & $-.201^{*}$ \\
\hline Trust & .147 & $.171^{*}$ & $-.178^{*}$ \\
\hline Partner warmth/closeness & $.302^{* * *}$ & $.375^{* * *}$ & $-.341^{* * *}$ \\
\hline Global rating & & & \\
\hline $\begin{array}{l}\text { Minimize negative impact } \\
\text { Attachment-irrelevant events }\end{array}$ & $.261^{* *}$ & $.280^{* * *}$ & $-.271^{* *}$ \\
\hline Love/security & .003 & .024 & -.015 \\
\hline Responsive & .026 & .103 & -.049 \\
\hline Trust & .081 & .010 & $-.170^{*}$ \\
\hline \multicolumn{4}{|l|}{ Global rating } \\
\hline Minimize negative impact & .078 & .066 & -.111 \\
\hline
\end{tabular}

Note. $N=135$.

$* p<.05 . \quad * * p<.01 . \quad * * * p<.001$, two-tailed.

times at least one attachment theme was mentioned for the two types of events. These scores were then correlated with the attachment dimensions. In response to attachment-relevant events, individuals who were comfortable depending on others were less likely to spontaneously mention an attachment theme ( $r=-.28, p<.001$ ), and those who were worried about being rejected were more likely to do so $(r=.19, p<.05)$. However, as expected, attachment style was unrelated to the presence of attachment themes for explanations in response to irrelevant events (all $r$ s nonsignificant).

Open-ended explanations: Continuous ratings of attachment themes. To test the hypothesis that attachment style would be associated with the positive and negative content of explanations, the attachment scales were correlated with the continuous explanation ratings. As shown in the upper panel of Table 1, working models of attachment were significantly associated with the content of explanations given in response to attachment-relevant events. Individuals who were comfortable with closeness and feit they could depend on others were more likely to provide explanations that indicated confidence in their relationship and in their partner's love, were less likely to view their partner's behavior as purposely rejecting closeness and, overall, were more likely to give explanations that minimized the negative impact of the event. In addition, people comfortable with closeness were more likely to provide explanations that reflected faith that their partner was responsive to their signals and was dependable when needed. And those who felt they could depend on others gave explanations that reflected greater trust in their partner.

As shown in Table 1, participants who were worried about being rejected and unloved provided explanations that offered a much more negative view of their partner and more negative interpretation of the event. Consistent with their working models, they were more likely to give explanations indicating that their relationship was in jeopardy and that their partner was unresponsive, not trustworthy, and was purposely rejecting 
closeness. In addition, their explanations reflected lower selfworth and self-reliance, and the overall content of their explanations tended to maximize the negative impact of their partner's behavior.

As shown in Table 1, working models of attachment were poor predictors of explanations for events designed to be irrelevant with respect to attachment issues. (Recall that the variables shown in Table 1 are only those that had adequate reliability.) The only significant relation that emerged was a small negative association between the anxiety subscale and partner trust. $T$-tests for nonindependent $r s$ were computed between these correlations and the comparable ones shown in Table 1. Five (42\%) of the 12 correlations were statistically larger for attachment events than for irrelevant events. Because the irrelevant events were not of interest for other outcome variables in this study, all remaining results are presented for attachment events only.

In summary, content coding of participants' open-ended explanations provided good support for the hypothesis that adults with different attachment styles would explain attachment-relevant events in ways consistent with their models of themselves and close relationships. Overall, individuals with a more secure attachment style (those who were comfortable with relationships and confident that they are loved) provided explanations that suggested positive beliefs about their partner and the security of their relationship. They tended to interpret events in ways that minimized their negative impact and limited their importance for broader issues of relationship stability. In contrast, people who were anxious about being unloved and felt they could not depend on others were much more likely to give explanations that contained negative attachment themes. They tended to view their partner as unresponsive and untrustworthy, and to view the behavior as a sign of rejection and as an indication that their relationship was in jeopardy. Overall, insecure adults interpreted events in ways that increased their negative impact for themselves and for the relationship.

Structured attribution dimensions. To examine attachment differences through more traditional measures of attribution, the attachment scales were correlated with participants' ratings of the structured attribution dimensions. As shown in Table 2, working models of attachment were significantly associated with variations in attributions. People who were comfortable with closeness and able to depend on others were less likely to attribute the partner's behavior to themselves (i.e., participant) or to their relationship. In addition, they were less likely to view the behavior as intentional and negatively motivated, and as something that the partner could control (i.e., voluntary). People who were comfortable depending on others were also less likely to view the cause as something that was not likely to change and as something that affected many areas of the relationship ( stable / global dimension).

Once again, anxiety about oneself in relationships was associated with more unfavorable attributions. Consistent with their negative expectations, individuals who were worried about being unloved were more likely to attribute their partner's behavior to something about the relationship and to their partner's negative attitude and motivation. In addition, they were more likely to view the behavior as caused by something that was unchanging and widespread (stable/global dimension).
Table 2

Correlations Between Attachment-Style Dimensions and Structured Attribution Dimensions, Emotional Responses, and Behavioral Intentions

\begin{tabular}{|c|c|c|c|}
\hline \multirow[b]{2}{*}{ Outcome variable } & \multicolumn{3}{|c|}{ Attachment-style dimensions } \\
\hline & Close & Depend & Anxiety \\
\hline \multicolumn{4}{|l|}{ Attribution ratings } \\
\hline Partner & -.043 & .079 & -.055 \\
\hline Circumstances & .008 & .141 & .009 \\
\hline Self & $-.272 * * *$ & $-.225^{* *}$ & .147 \\
\hline Relationship & $-.287^{* * *}$ & $-.244 * *$ & $.189^{*}$ \\
\hline Negative attitude/intentions & $-.342^{* * *}$ & $-.309^{* * *}$ & $.208^{* *}$ \\
\hline Stable/global & -.144 & $-.235 * *$ & $.237^{* * *}$ \\
\hline Voluntary/controllable & $-.211^{*}$ & $-.234^{* *}$ & .004 \\
\hline \multicolumn{4}{|l|}{ Emotional responses } \\
\hline Distress & $-.248^{* *}$ & $-.246^{* *}$ & $.499^{* * * *}$ \\
\hline Nervousness & $-.186^{*}$ & $-.179^{*}$ & $.496^{* * *}$ \\
\hline Unemotional & -.015 & .077 & -.139 \\
\hline \multicolumn{4}{|l|}{ Behavioral responses } \\
\hline Self-ratings of conflict & $-.338^{* * *}$ & $-.348 * * *$ & $.338 * * *$ \\
\hline $\begin{array}{l}\text { Ratings of behavioral } \\
\text { intentions }\end{array}$ & $-.224^{* *}$ & $-.259 * *$ & $.171^{*}$ \\
\hline
\end{tabular}

$* p<.05 . * 0<.01 . * * * p<.001$, two-tailed.

Emotional responses. Correlations between the attachment dimensions and emotional responses are presented in Table 2. As predicted, anxiety about relationships was strongly correlated with negative emotional responses. People who were worried about being unloved were much more likely to experience emotional distress and nervousness (e.g., feeling confused, nervous, and helpless). In contrast, individuals who were comfortable with closeness and were able to depend on others were less likely to respond with strong negative emotions. Contrary to expectations, working models of attachment were not related to participants' reports about feeling unemotional.

Behavioral intentions. Finally, the attachment dimensions were correlated with two measures of behavioral intentions. The first measure was participants' own predictions about the likelihood that the event would result in conflict. The second measure was independent ratings of participants' cpen-ended responses describing how they would behave toward their partner in each situation. As shown in Table 2, attachment dimensions were strongly related to participants' own ratings of the likelihood of conflict. People who were comfortable with closeness and were able to depend on others were much less likely to predict conflict than those who were anxious about being unloved. Although it is difficult to determine the source of these expectations, past research suggests that secure adults are likely to have both more positive beliefs about their own behavioral tendencies and more optimistic expectations for the behavior of others. Attachment was also related to ratings of specific behavioral intentions, although the relations were not as strong. Individuals who were comfortable with closeness and were able to depend on others were less likely to behave in ways rated as punishing toward their partner or as likely to result in conflict, whereas those who were anxious about being unloved were somewhat more likely to do so. 
Table 3

Mean Differences on Attachment-Style Dimensions for Attachment Styles Derived From a Cluster Analysis

\begin{tabular}{lcccc}
\hline & \multicolumn{3}{c}{ Cluster/attachment style } & \\
\cline { 2 - 4 } Attachment & $\begin{array}{c}\text { Secure } \\
\text { dimension }\end{array}$ & $\begin{array}{c}\text { Avoidant } \\
(N=68)\end{array}$ & $\begin{array}{c}\text { Preoccupied } \\
(N=25)\end{array}$ & $F(2,132)$ \\
\hline Close & $4.02_{\mathrm{a}}$ & $3.20_{\mathrm{b}}$ & $3.03_{\mathrm{b}}$ & $47.75^{* * * *}$ \\
Depend & $3.69_{\mathrm{a}}$ & $2.58_{\mathrm{b}}$ & $2.44_{\mathrm{b}}$ & $94.74^{* * * *}$ \\
Anxiety & $2.53_{\mathrm{a}}$ & $2.48_{\mathrm{a}}$ & $4.05_{\mathrm{b}}$ & $63.59^{* * * *}$ \\
\hline
\end{tabular}

Note. Scores can range from I to 5 . Within rows, means with different subscripts differ at $p<.05$, according to a Newman-Keuls Multiple Comparison test.

*** $p<.001$.

\section{Mean Differences on All Outcome Variables by Attachment Style}

Although the continuous attachment dimensions provide a more detailed analysis of the relationships between adult attachment and other variables of interest, it is useful theoretically and conceptually to consider differences between discrete attachment-style groups. To accomplish this, a cluster analysis of the continuous dimensions (close, depend, and anxiety) was used to categorize people into discrete attachment styles, and mean differences between groups were examined for all outcome variables. Because these results are partially redundant with those presented already, they are described only briefly.

Categorizing into styles with cluster analysis. On the basis of procedures described by Collins and Read (1990), the three dimensions of the AAS were used to assign people to attachment styles through cluster analysis (a similar method was used by Feeney, Noller, \& Hanrahan, 1994). A cluster analysis using Ward's method and squared Euclidean distance was performed by the Cluster subprogram of the Statistical Package for the Social Sciences (SPSS). Scores on close, depend, and anxiety were used as the clustering variables. Several heuristic techniques discussed by Aldenderfer and Blashfield (1984; described fully in Collins \& Read, 1990) were used to determine the optimal number of clusters. ${ }^{5}$ On the basis of these, the three-cluster solution was viewed as the most reasonable representation of the data.

As shown in Table 3, the three clusters corresponded closely to theoretical descriptions of the three attachment styles, and each cluster has been labeled accordingly. The group labeled "secure" was comfortable with closeness, able to depend on others, and not worried about being unloved. Those labeled "avoidant" were uncomfortable with closeness, not able to depend on others, and not worried about being unloved. Finally, the group labeled as "preoccupied" was uncomfortable with closeness, uncomfortable with depending on others, and was very high in fear of abandonment. Fifty percent of the sample was categorized as secure, $31 \%$ as avoidant, and $19 \%$ as preoccupied. These percentages correspond closely to previous studies that used this methodology.

Open-ended explanation ratings. A multivariate analysis of variance (MANOVA) on the ratings of attachment themes re- vealed a significant multivariate effect of attachment style, Wilks' lambda $=.83, F(12,252)=2.03, p<.05$. Means for each attachment style and univariate $F$-tests appear in Table 4.

Those with a secure attachment style offered explanations that were more positive than did participants with either of the insecure styles. The preoccupied style always obtained the lowest score on each dimension, reflecting the most negative explanations overall. These findings confirm those obtained with the continuous attachment scales, suggesting that people with a secure attachment style interpreted the event in a way that minimized its negative effect, whereas people with a more insecure style were likely to maximize the event's negative impact.

Structured attribution dimensions. A MANOVA on the seven structured attribution measures revealed a significant multivariate effect of attachment style, Wilks' lambda $=.72$, $F(14,252)=3.19, p<.01$. Means for each style and univariate $F$-tests appear in Table 4 . Consistent with the correlational findings, significant univariate effects were obtained for all variables except attributions to partner and to circumstances.

Those with a secure attachment style were less likely to attribute their partner's behavior to themselves, to something negative about their relationship, and to something global and stable. They were also less likely to view their partner as having acted with negative intentions. In contrast, avoidant and preoccupied adults were more likely to attribute the behavior to something about themselves and their relationship. They were also more likely to view their partner as having behaved intentionally and as negatively motivated. In addition, avoidant adults were more likely to believe that their partner's negative behavior was caused by something the partner could have controlled, and preoccupied adults believed the behavior was caused by something that was stable and not likely to change.

In summary, as expected, people with a secure attachment style were more likely to make benign attributions for their partner's behavior, whereas those with a more insecure style tended to make unfavorable attributions that suggested stable causes and negative motivations. It is noteworthy that the pattern shown by secure individuals is similar to the pattern exhibited by partners in nondistressed couples in studies of attributions and marital satisfaction, whereas the pattern shown by insecure individuals is typical of that displayed by members of distressed couples.

Emotional responses. A MANOVA on the three emotion indices (distress, nervousness, and unemotional) revealed a significant multivariate effect of attachment style, Wilks' lambda

\footnotetext{
${ }^{5}$ Several heuristic techniques were used to determine the number of distinguishable clusters (Aldenderfer \& Blashfield, 1984). One procedure is to graph the number of clusters against the amalgamation coefficient, which represents the degree of similarity among cluster members. The curve is then examined for the point at which it flattens, suggesting that similarity among cluster members has been greatly reduced. A second, related procedure is to examine the amalgamation coefficient for each cluster solution (starting with the maximum number of clusters and working downward) to discover a significant jump in the value of the coefficient. A large jump implies that two dissimilar clusters have been merged, suggesting that the number of clusters prior to the merger is a reasonable solution. Of course, neither of these procedures provides definitive evidence for a cluster solution, and they should be used in conjunction with theoretical and conceptual considerations.
} 
Table 4

Mean Differences on All Outcome Measures by Attachment Style: Study 1

\begin{tabular}{lllll}
\hline \multicolumn{1}{c}{ Outcome variable } & Secure & Avoidant & Preoccupied & $F(2,132)$ \\
\hline Open-ended explanation ratings & & & & \\
Love/security & $5.48_{\mathrm{a}}$ & $5.07_{\mathrm{b}}$ & $4.76_{\mathrm{b}}$ & $6.01^{* * *}$ \\
Responsive/dependable & $4.69_{\mathrm{a}}$ & 4.57 & $4.43_{\mathrm{b}}$ & $3.57^{*}$ \\
Self-worth/reliance & 5.46 & 5.31 & 5.24 & 1.64 \\
Trust & 5.77 & 5.56 & 5.52 & 1.62 \\
Partner warmth/closeness & $4.84_{\mathrm{a}}$ & $4.64_{\mathrm{b}}$ & $4.50_{\mathrm{b}}$ & $9.85^{* * *}$ \\
Global rating & & & & \\
$\quad$ Minimize negative impact & $5.72_{\mathrm{a}}$ & $5.02_{\mathrm{b}}$ & $4.63_{\mathrm{b}}$ & $6.62^{* *}$ \\
Attribution ratings & & & & \\
Partner & 5.41 & 5.64 & 5.37 & 0.78 \\
Circumstances & 5.57 & 5.15 & 5.58 & 2.17 \\
Self & $3.66_{\mathrm{a}}$ & $4.30_{\mathrm{b}}$ & $4.27_{\mathrm{b}}$ & $4.77^{* *}$ \\
Relationship & $3.58_{\mathrm{a}}$ & $4.14_{\mathrm{b}}$ & $4.62_{\mathrm{b}}$ & $6.27^{* *}$ \\
Negative attitude/intentions & $2.75_{\mathrm{a}}$ & $3.54_{\mathrm{b}}$ & $3.66_{\mathrm{b}}$ & $9.79^{* * *}$ \\
Stable/global & $3.38_{\mathrm{a}}$ & $3.57_{\mathrm{a}}$ & $4.08_{\mathrm{b}}$ & $4.65^{*}$ \\
Voluntary/controllable & $4.44_{\mathrm{a}}$ & $5.14_{\mathrm{b}}$ & 4.94 & $5.78^{* * *}$ \\
Emotional responses & & & & \\
Distress & $3.27_{\mathrm{a}}$ & $3.67_{\mathrm{a}}$ & $4.41_{\mathrm{b}}$ & $11.21^{* * *}$ \\
$\quad$ Nervousness & $2.74_{\mathrm{a}}$ & $2.78_{\mathrm{a}}$ & $3.85_{\mathrm{b}}$ & $10.75^{* * *}$ \\
Unemotional & 2.41 & 2.31 & 2.23 & 0.38 \\
Behavioral responses & & & & \\
Self-ratings of conflict & $3.29_{\mathrm{a}}$ & $4.07_{\mathrm{b}}$ & $4.49_{\mathrm{b}}$ & $15.07^{* * *}$ \\
Ratings of behavioral intentions & 2.81 & 3.30 & 3.14 & $2.59+$ \\
\hline
\end{tabular}

Note. Scores for the explanation ratings can range from 1 to 9 (recoded from -4 to +4 ); all other scores range from 1 to 7 . Within rows, means with different subscripts differ at $p<.05$, according to a NewmanKeuls Multiple Comparison test.

${ }^{*} p<.05 .{ }^{* *} p<.01 .^{* * *} p<.001 . \quad \dagger p<.10$.

$=.81, F(6,260)=4.93, p<.001$. Means for each attachment style and univariate $F$-tests appear in Table 4 . Consistent with the correlational findings, significant univariate effects were obtained for distress and nervousness, but not for unemotional. As predicted, preoccupied individuals were much more likely to experience emotional distress. However, the hypothesis that avoidant people would deny emotional responses was only partially supported. Although they did report less negative emotion than the preoccupied group (despite providing equally negative explanations), they were not more likely to report feeling unemotional or indifferent in response to the events.

Behavioral intentions. As shown in Table 4, strong differences were found on participant's own conflict ratings, with the secure group being much less likely to predict conflict than either the avoidant or preoccupied group. Although the $F$-test for the behavioral descriptions was only marginally significant, the pattern of means suggests that secure individuals were less likely to behave in ways that would be punishing and likely to result in conflict.

Gender differences. To determine if attachment style differences varied for men and women, a series of 2 (sex) $\times 3$ (attachment style) MANOVAs was conducted for all outcome variables. Although there were several significant main effects for gender, there were no significant interactions between attachment style and gender for any of the outcome variables. ${ }^{6}$

\section{Mediational Model Linking Attachment, Explanation, Emotion, and Behavior}

Specifying the model. Results based on both the continuous attachment dimensions and the discrete styles indicate that peo- ple with different working models of attachment interpreted and responded to the same events in very different ways. However, these results do not provide information about the interrelations among cognitive, emotional, and behavioral processes. Thus, the final step was to test the structural model hypothesized to underlie these relations. The hypothesized model specified the following paths: (a) direct paths from working models of attachment to explanations and emotions, (b) a direct path from explanations to emotions, and (c) direct paths from explanations and emotions to behavioral intentions. ${ }^{7}$

Although it would be ideal to include several indicators for each construct in the model (i.e., to form latent variables of each construct), the sample size was not large enough to reliably test such a model. Therefore, I tested the model by choos-

\footnotetext{
${ }^{6}$ Because sex differences in explanation were not the focus of this study, these findings are not presented. However, a summary of these results is available from N.L. Collins.

${ }^{7}$ As noted above, the full model presented by Collins and Read (1994) included a reciprocal link from emotional responses to cognitive processing. Although I believe that emotions may have an important impact on cognitive processing, these processes were not the focus of, and could not be adequately addressed in, the present studies. Emotional responses were made after participants had completed their openended explanations and had responded to additional explanation questions that were not analyzed for this article. Because explanations preceded the emotion ratings temporally in these studies, and because only one path could be estimated at a time, it was more reasonable to estimate the path leading from explanations to emotions. Ideally, both paths would be estimated, but such a model could not be properly tested with these data.
} 
ing the single indicator that best represented each theoretical construct. First, the continuous attachment dimensions were preferred over dummy-coding the three attachment styles because the dimensions are more sensitive and provided a more straightforward means of analysis. However, because the three subscales were correlated, problems of multicollinearity might result if all three were included in the model. Thus, the close and depend dimensions were combined into a single scale for several reasons. Most important, these two subscales are conceptually related in that both are thought to be most closely associated with models of others (vs. models of the self). The two scales are also fairly strongly correlated $(r=.53)$, and were related to most of the outcome variables in a similar way. Second, to assess explanation patterns I used the judges' ratings of the overall negative impact of the open-ended explanations because it was the best global, summary rating of the explanations and because judges' ratings on this global dimension seemed to be largely a function of the more specific attachment theme ratings. This idea was confirmed by a regression analysis that indicated that over $90 \%$ of the variance in this global rating was accounted for by variance in the eight attachment-theme ratings. Next, the emotional distress index was chosen to represent emotional responses because it was the most general measure of negative affect. Finally, independent ratings of participants' written behavioral responses were used to represent behavioral intentions.

To test the model, EQS (Bentler, 1989) software for structural equation modeling was used. Because only one measured variable was used for each hypothetical variable, this analysis is simply a path analysis. The goodness of fit of the model was assessed with a joint consideration of the chi-square test and the comparative fit index (CFI; Bentler \& Bonett, 1980). A nonsignificant chi-square indicates a good-fitting model. The CFI can range from 0 to 1.0 , a value of .95 or greater indicating a goodfitting model, although values between .90 and .94 are considered acceptable (Bentler \& Bonett, 1980).

Testing the mediational model. First, the hypothesized model was estimated, resulting in a $\chi^{2}(2, N=135)=4.73, p=$ $.09, \mathrm{CFI}=.98$. Although these fit statistics were very good, the path linking the close-depend composite with emotional distress was not significant $(\beta=.06)$, and the path linking anxiety to explanation patterns was marginally significant $(\beta=.16, p$ $=.07$ ). Thus, the link between close-depend and distress was removed, resulting in a small improvement in model fit, $\chi^{2}(3$, $N=135)=5.27, p=.15, \mathrm{CFI}=.99$. An additional model was tested in which the marginal path between anxiety and explanation patterns was removed, but this resulted in decreased model fit. In addition, the link between anxiety and explanation patterns resulted in the largest modification index (as indicated by the Lagrange multiplier test), which indicated that including that path would provide the largest improvement in model fit. Thus, this link was retained. Because model fit was good, no additional paths were added. Parameter estimates for the final model are shown in Figure 2.

As hypothesized, working models of attachment predicted explanations, with both close-depend and anxiety providing independent contributions. Emotional distress was directly associated with anxiety as well as with explanations: Specifically, fear about being unloved and negative explanations predicted greater emotional distress. Close-depend did not have a direct link to emotions, only an indirect one mediated through explanations. Finally, both explanations and emotions uniquely contributed to behavioral intentions: Specifically, negative interpretations of the event and emotional distress resulted in intended behavior that was more punishing and more likely to lead to conflict.

An additional model was run in which direct paths were added between the two attachment dimensions and behavioral intentions. Neither of these paths were statistically significant. Thus, as hypothesized, there were no direct effects between attachment style and behavioral intentions, only indirect ones mediated through cognitive and emotional response patterns.

Finally, to be sure that the modeling results were not dependent on the particular explanation variable used, the same model was run with a latent explanation variable that included all eight of the attachment theme ratings. The regression coefficients for this model, and the conclusions drawn from them, were virtually identical to those for the more simple model. The only difference in this model was that, in addition to significant links between the attachment variables and the latent explanation variable, there were unique relationships between the attachment variables and the residuals for several explanation dimensions.

\section{Study 2}

Study 1 provides support for the idea that differences in $\operatorname{cog}$ nitive models associated with attachment styles predispose people to think, feel, and behave differently in response to the same relationship events. Nevertheless, because participants were responding to hypothetical partners on the basis of very restricted information, the generalizability of these results to people in ongoing relationships may be somewhat limited. In established relationships, couple members should operate on the basis of several sources of social knowledge, some of which are based on relatively stable models of self and others that are brought into the relationship (i.e., an attachment style), and some of which are based on cognitive representations of their specific partner and specific relationship (i.e., the history and quality of one's current relationship). This partner-specific model may include such things as memories of the partner's past behavior, beliefs about the partner's stable dispositions, perceptions of a partner's commitment to the relationship, and so on. Within the present framework, the representation of one's current relationship is viewed as an additional knowledge structure or working model that will be activated whenever relationship-relevant events are experienced (Collins \& Read, 1994). Of course, concrete, relationship-specific models are not expected to be independent of more abstract attachment models, nor are they considered objective representations of actual experience. These models are best viewed as constructions of social reality that are linked in complex ways with more stable models of self and others (Collins \& Read, 1994).

The aim of Study 2 was to replicate Study 1 with people involved in ongoing dating relationships, and to test the relative contributions of attachment style and relationship quality to predicting patterns of explanation, emotion, and behavior. It was expected that attachment style would continue to predict 


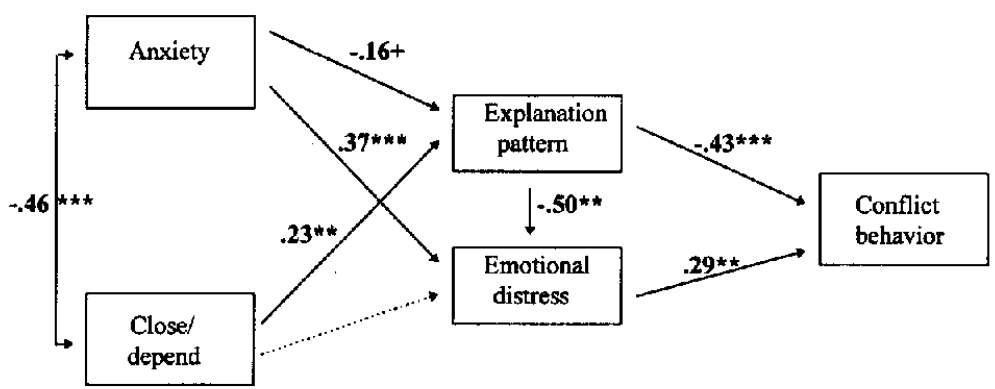

$$
\begin{aligned}
& \chi^{2}(3)=5.27, p=.15 \quad C F I=.99 \quad N=135 \\
& +p<.10 \quad{ }^{*} p<.05 \quad * * p<.01 \quad{ }^{* * *} p<.001
\end{aligned}
$$

Figure 2. Final parameter estimates and goodness-of-fit statistics for the mediational model in Study 1. Numbers on double-headed arrows are correlation coefficients; numbers on single-headed arrows are standardized regression coefficients. Dashed lines indicate nonsignificant paths that were dropped from the final model. CFI = comparative fit index.

outcomes even after accounting for relationship-specific models. Once again, attachment-relevant events were compared to irrelevant events to demonstrate the functional specificity of attachment representations. It was predicted that attachment style differences in explanations would be more evident in response to attachment-relevant relationship events.

Finally, a mediational model linking attachment style and relationship quality to explanation, emotion, and behavior was proposed and tested. This model was similar to the model tested in Study 1, but with two additions: (a) Relationship quality was added to the model and was expected to directly predict explanation patterns, and (b) because attachment style has been shown to predict relationship quality, correlational paths linking attachment style and relationship quality were also included. Consistent with prior research on attributions in marriage, relationship quality was expected to have only an indirect relationship with emotional responses, mediated through explanations.

\section{Method}

Study 2 was identical to Study 1 except that all participants were involved in a romantic relationship and were asked to respond to the materials in terms of their current partner rather than a hypothetical partner. Participants also completed a questionnaire on relationship quality and responded to one additional attachment-irrelevant event. The additional irrelevant event was added because, in Study 1, differences between attachment relevant and irrelevant events may have resulted in part from the irrelevant events having not been measured as reliably. Although it would have been ideal to have had four events in each category, this would have been too taxing for both participants and raters.

\section{Participants}

Participants were 56 male and 73 female undergraduate students from the University of Southern California who participated for extra credit in their introductory psychology course. Participants ranged in age from 17 to 30 years old, with a mean age of 19.2. To participate, it was required that participants be currently involved in a romantic relationship. Relationship length ranged from I to 96 months, with a mean of 16 months and a median of 12 months. Over $75 \%$ of the sample reported that they had been dating their partner longer than 4 months, and $85 \%$ were dating their partner exclusively.

\section{Materials}

Participants completed three sets of materials: (a) a background questionnaire, (b) a relationship events questionnaire, and (c) an attribution questionnaire.

The background questionnaire contained the AAS and measures of demographic characteristics that were identical to those in Study 1. Reliability coefficients for the close, depend, and anxiety subscales in the present sample were $.82, .80$, and .83 , respectively. The close and depend subscales were strongly correlated $(r=.67)$, and the anxiety subscale was moderately correlated with the close $(r=-.28)$ and depend $(r=$ $-.46)$ subscales. There were no differences between men and women on the three attachment dimensions, and there were no significant correlations between relationship length and the subscales of the AAS.

To assess relationship quality, participants completed a 15 -item measure adapted from the one used by Collins and Read (1990) in their work on relationship satisfaction in dating couples. Some of these items originated from widely used measures of marital satisfaction (Locke \& Wallace, 1959; Spanier, 1976), whereas others were developed specifically for use with dating couples. Items focused on five aspects of relationship quality: (a) general satisfaction, (b) communication, (c) feeling understood and accepted by one's partner, (d) frequency and severity of conflict, and (e) participant's own level of commitment and perception of their partner's commitment. The 15 items were standardized and averaged to form a single index of relationship quality. Coeffcient alpha for this index was .84. As expected, relationship satisfaction was significantly correlated with the attachment-style dimensions. Individuals who reported higher quality relationships were more comfortable with closeness $(r=.23, p<.05)$ and with depending on others $(r=$ $.24, p<.05$ ), and were less worried about being rejected or abandoned $(r=-.29, p<.001)$.

The relationship events and attribution questionnaires were identical to those used in Study 1, except for the addition of one more irrelevant event, making a total of seven partner behaviors (four attachment-relevant and three irrelevant). This additional event read, "Please imagine that your partner arrived for your date thirty minutes late." As in Study 1 , three emotion composites (distress, nervousness, and unemotional) 
were computed from the emotion ratings, and some of the attribution ratings that were highly correlated and conceptually related were combined.

\section{Procedure}

The experimental procedure was identical to that in Study 1, except that participants were given slightly different instructions directing them to think about their current relationship partner rather than a fictitious dating partner.

Coding open-ended explanations. Open-ended explanations were coded on the same nine content dimensions used in Study 1, and the procedures for preparing and coding the explanations were identical to those followed in Study 1. Ratings were conducted by one male and one female coder. The female rater had also coded Study 1 , and the male rater was new. The reliability coefficients for the overall sample were very comparable to those obtained in Study 1. For the full sample of events, coefficients ranged from .82 to .95 , indicating strong agreement between raters on all nine dimensions. As in Study 1, reliability estimates were also computed separately for the two types of events. Coefficients ranged from .84 to .95 for ratings of attachment-relevant events, and from .74 to .92 for attachment-irrelevant events. However, for attachment-irrelevant events, two of the dimensions (self-reliance and warmth) were rated as neutral more than $90 \%$ of the time by one or both raters, which resulted in almost zero variance and very low reliability estimates. As such, these two dimensions were not used to test relationships between attachment and explanations for irrelevant events.

The intercorrelations among the ratings were very comparable with those obtained in Study 1. Once again, although many dimensions were moderately correlated, coders were able to successfully distinguish between the various dimensions. However, as in Study 1, three pairs of variables had fairly substantial correlations and were also conceptually related, so they were averaged as follows: love with secure $(r=.89)$; responsive with dependable $(r=.70)$; and self-worth with self-reliance $(r=.76)$

Coding behavioral intentions. The procedure for coding the written behavioral descriptions was identical to that in Study 1. Coding was conducted by one male and one female rater. The male rater had also coded Study 1, and the female rater was new. Each rater coded half the questionnaires, and interrater reliability was assessed by having the raters code a random selection of each other's questionnaires, totaling $23 \%$ of the sample ( 210 responses overall). The reliability coefficient was .88 for ratings of punishing and .86 for ratings of conflict, indicating strong interrater agreement on both dimensions. The two dimensions were strongly correlated for both coders $(r=.92$ and .94$)$, and were therefore averaged.

\section{Results and Discussion}

\section{Open-Ended Explanations: Explicit Attachment Themes}

To test the prediction that attachment-relevant events would be more likely to elicit attachment content than irrelevant events, the likelihood of having at least one explicit attachment theme was compared for the two set of events. As expected, participants were more likely to spontaneously mention an attachment theme in response to attachment events, $\chi^{2}(1, N=129)$ $=24.60, p<.001$. On average, $34 \%$ of explanations for attachment events contained at least one of the eight attachment themes, compared with only $19 \%$ for irrelevant events.

To determine if participants with different working models were more or less likely to mention explicit attachment themes, composite scores were computed to indicate the number of times at least one attachment theme was mentioned for the two types of events. There were no significant correlations between these two scores and any of the three attachment dimensions. However, participants who were more satisfied with their current relationship mentioned fewer attachment themes in response to attachment-relevant events $(r=-.21, p<.05)$, but not to the attachment-irrelevant events $(r=-.02)$.

\section{Regression Analyses Predicting All Outcomes by Attachment Dimensions and Relationship Quality}

Open-ended explanations: Continuous ratings of attachment themes. First, to explore the relative contributions of attachment style and current relationship quality to the content of free-response explanations, the attachment scales and the relationship quality index were used as predictor variables in a series of simultaneous multiple regression analyses. Because the close and depend subscales were strongly correlated in this sample, are conceptually similar, and tend to be related to other variables in similar ways, the two scales were combined into a single index for all regression analyses.

As shown in the upper panel of Table 5, the regression equation was significant for all variables, with both relationship quality and the anxiety dimension making significant unique contributions. The three variables together accounted for between $9 \%$ and $21 \%$ of the variance in the ratings of explanation content for attachment-relevant events. In every case, participants who were in relationships that they perceived as satisfying and committed were less likely to interpret their partner's behavior in a way that reflected negative attachment themes. In contrast, and independent from relationship quality, the extent to which a person was worried about being rejected and unloved (i.e., anxiety subscale) consistently predicted the presence of negative attachment themes. In contrast to Study 1, a person's comfort with closeness and ability to depend on others was not related to their explanations.

As predicted, individual differences in attachment style did not explain differences in attachment-irrelevant events. As shown at the bottom of Table 5, working models of attachment were not significantly associated with any of the explanation dimensions. Relationship quality was also less consistently related to this set of explanations, although several significant effects did emerge. Specifically, participants with better-quality relationships provided explanations that reflected high selfworth and confidence in their partner's responsiveness. In addition, their explanations were rated, generally, as minimizing the negative impact of their partner's behavior.

The primary aim of Study 2 was to test the relative contributions of attachment style and relationship quality to predicting responses to potentially distressing relationship events. As expected, individuals in satisfying and committed relationships viewed potentially negative events in a less threatening way, minimizing their impact for broader issues of relationship security. However, working models of attachment still remained an important, independent predictor of explanation patterns. In contrast to Study 1 , however, anxiety was the only attachment dimension that consistently predicted. Overall, individuals who were worried about being rejected and unloved appeared pre- 
Table 5

Multiple Regression Analyses Predicting Open-Ended Explanation Ratings From Relationship Quality and Attachment-Style Dimensions

\begin{tabular}{|c|c|c|c|c|c|}
\hline \multirow[b]{2}{*}{ Outcome variable } & \multicolumn{3}{|c|}{ Predictor variables } & \multirow[b]{2}{*}{$R$} & \multirow[b]{2}{*}{$R^{2}$} \\
\hline & $\mathbf{R Q}$ & Close/depend & Anxiety & & \\
\hline \multicolumn{6}{|l|}{ Attachment-relevant events } \\
\hline Love/security & $.30^{* * *}$ & -.13 & $-.22 *$ & .39 & $.15^{* * *}$ \\
\hline Responsive/dependable & $.30^{* * * *}$ & -.15 & $-.24 * *$ & .40 & $16^{* * *}$ \\
\hline Self-worth/reliance & $.22 *$ & -.11 & $-.18^{*}$ & .30 & $.09^{* *}$ \\
\hline Trust & $.28^{* * *}$ & -.08 & $-.23^{*}$ & .38 & $.15^{* * * *}$ \\
\hline Partner warmth/closeness & $.31^{* * * *}$ & -.07 & $-.29^{* * *}$ & .46 & $.21^{* * *}$ \\
\hline Global rating & & & & & \\
\hline Minimize negative impact & $.31 * * *$ & -.10 & $-.21^{*}$ & .40 & $.16^{* * * *}$ \\
\hline \multicolumn{6}{|l|}{ Attachment-irrelevant events } \\
\hline Love/security & .15 & .05 & -.12 & .24 & $.06^{*}$ \\
\hline Responsive/dependable & $.18^{*}$ & .06 & -.12 & .27 & $.07^{* *}$ \\
\hline Self-worth & $.19^{*}$ & .08 & -.14 & .30 & $.09^{* *}$ \\
\hline Trust & .14 & .04 & -.05 & .17 & .03 \\
\hline \multicolumn{6}{|l|}{ Global rating } \\
\hline Minimize negative impact & $.30^{* * * *}$ & .03 & -.05 & .33 & $.11^{* *}$ \\
\hline
\end{tabular}

Note. Unless otherwise labeled, values shown are standardized regression coefficients. $R Q=$ relationship quality.

$* p<.05 . \quad * * p<.01 .^{* * *} p<.001$.

disposed to interpret events in ways that were consistent with their expectations, even if their current relationship was going well. As expected, attachment style did not predict the content of explanations for irrelevant events. In addition, for all participants, explanations for attachment-irrelevant events were much less likely to contain any explicit mention of attachment themes. These findings replicate those of Study 1 and provide further evidence that working models of attachment are, to some extent, selectively activated or used. Moreover, these results suggest that differences found in response to attachmentrelevant events were driven by the activation of attachment models rather than some more general perceptual bias.

Structured attribution measures. Regression analyses for the structured attribution ratings are presented at the top of Table 6 . In contrast to Study 1 , these ratings were not strongly predicted by either attachment or relationship quality. Only two significant equations were obtained. First, individuals who were in better quality relationships and were not worried about being rejected were less likely to attribute their partner's behavior to something about their relationship. Second, those who were anxious about being unloved were more likely to believe that the event was caused by something that affected many areas of the relationship and was not likely to change. They also had a tendency to believe that their partner's behavior was caused by something about themselves (i.e., about the participant).

Emotional responses. As shown in the middle of Table 6, anxiety was strongly associated with increased distress and nervous feelings, as predicted. Those who were comfortable with closeness were also more likely to report distress, although not nervousness. This finding is consistent with the prediction that secure participants (i.e., those comfortable with closeness and dependency) should be more willing than avoidant participants (who are much lower on these dimensions) to acknowledge distress. None of the predictors was significantly related to a re- ported lack of emotion. Also, as expected, relationship quality was not associated with emotional responses.

Behavioral intentions. As shown at the bottom of Table 6, people who were anxious about being unloved and those who were in poor quality relationships were more likely to anticipate conflict. However, only anxiety predicted whether the actual behaviors participants said they would engage in were judged to be punishing and likely to result in conflict.

\section{Mean Differences for Discrete Attachment Types}

Categorizing into styles with cluster analysis. On the basis of procedures described in Study 1, a cluster analysis was performed using scores on close, depend, and anxiety subscales as the clustering variables. Consistent with Study 1, there was good evidence for a three-cluster solution. The mean scores on close, depend, and anxiety for the three clusters were then examined ( see Table 7). The pattern of means was very consistent with theoretical accounts of the three attachment styles and with the pattern obtained in Study 1. The three clusters were therefore retained and labeled accordingly. It is noteworthy that only $9 \%$ ( $n=12$ ) of the sample was categorized as avoidant, which is somewhat lower than typically found in studies of dating couples.

Open-ended explanation ratings. A MANOVA on the openended explanations revealed a significant multivariate effect of attachment style, Wilks' lambda $=.84, F(12,242)=1.86, p$ $<.05$. As shown in Table 8 , significant univariate effects were obtained for all dependent variables. For each variable, the secure group was much less likely than the preoccupied group to have negative attachment themes. However, in contrast to Study 1 , the avoidant group gave explanations that were generally as favorable as those of the secure group, although the comparison did not always reach significance. 
Table 6

Multiple Regression Analyses Predicting Attributions, Emotions, and Behavioral Intentions

\begin{tabular}{|c|c|c|c|c|c|}
\hline \multirow[b]{2}{*}{ Outcome variable } & \multicolumn{3}{|c|}{ Predictor variables } & \multirow[b]{2}{*}{$R$} & \multirow[b]{2}{*}{$R^{2}$} \\
\hline & $\mathbf{R Q}$ & Close/depend & Anxiety & & \\
\hline \multicolumn{6}{|l|}{ Attribution ratings } \\
\hline Partner & -.01 & .09 & .19 & .18 & .03 \\
\hline Circumstances & .12 & $-.20^{*}$ & -.09 & .20 & .04 \\
\hline Self & -.02 & .04 & $.20^{*}$ & .19 & .04 \\
\hline Relationship & $-.18^{*}$ & .10 & $.32^{* * *}$ & .38 & $.14^{* * * *}$ \\
\hline Negative attitude/intention & -.08 & .05 & .15 & .18 & .03 \\
\hline Stable/global & -.17 & .11 & $.31^{* * *}$ & .35 & $.12^{* * *}$ \\
\hline Voluntary/controllable & -.11 & -.08 & -.13 & .15 & .02 \\
\hline \multicolumn{6}{|l|}{ Emotional responses } \\
\hline Distress & -.06 & $.21^{*}$ & $.51^{* * * *}$ & .49 & $.24^{* * *}$ \\
\hline Nervousness & .04 & .17 & $.47^{* * *}$ & .43 & $.18^{* * *}$ \\
\hline Unemotional & .14 & -.14 & -.11 & .20 & .04 \\
\hline \multicolumn{6}{|l|}{ Behavioral responses } \\
\hline Self-ratings of conflict & $-.26^{* *}$ & .16 & $.32^{* * * *}$ & .43 & $.18^{* * *}$ \\
\hline Ratings of behavioral intentions & -.13 & .13 & $.29^{* *}$ & .31 & $.10^{* *}$ \\
\hline
\end{tabular}

Note. Unless otherwise labeled, values shown are standardized regression coefficients. $R Q=$ relationship quality.

${ }^{*} p<.05 . \quad * * p<.011^{* * *} p<.001$

Structured attribution measures. Consistent with the regression analyses, the attribution ratings were not strongly associated with attachment style. A MANOVA revealed a nonsignificant multivariate effect of attachment style, Wilks' lambda $=.85, F(14,240)=1.50, p>.10$. Significant univariate effects were obtained only for ratings of relationship as the cause, $F(2$, $126)=5.93, p<.01$, and for ratings of negative motivation, $F(2,126)=4.32, p<.05$. In both cases, the preoccupied group gave more pessimistic attributions than either the secure or avoidant group.

Emotional responses. A MANOVA on the three emotion indices revealed a significant multivariate effect of attachment style, Wilks' lambda $=.82, F(6,248)=4.19, p<.01$. Signifcant univariate effects were obtained on all three indexes, as shown in the middle of Table 8. As predicted, the avoidant group was least likely to report feeling distress and more likely to report feeling unemotional in response to their partner's behavior. Also, as predicted, the secure group was more distressed

Table 7

Mean Differences on Attachment-Style Dimensions for Attachment Styles Derived From a Cluster Analysis: Study 2

\begin{tabular}{lcccc}
\hline & \multicolumn{3}{c}{ Cluster/attachment style } & \\
\cline { 2 - 4 } Attachment & $\begin{array}{c}\text { Secure } \\
\text { dimension }\end{array}$ & $\begin{array}{c}\text { Avoidant } \\
(N=64)\end{array}$ & $\begin{array}{c}\text { Preoccupied } \\
(N=53)\end{array}$ & $F(2,126)$ \\
\hline Close & $4.41_{\mathrm{a}}$ & $2.36_{\mathrm{b}}$ & $3.29_{\mathrm{c}}$ & $115.62^{* * * *}$ \\
Depend & $4.04_{\mathrm{a}}$ & $2.29_{\mathrm{b}}$ & $2.89_{\mathrm{c}}$ & $92.64^{* * * *}$ \\
Anxiety & $1.96_{\mathrm{a}}$ & $2.22_{\mathrm{a}}$ & $3.13_{\mathrm{b}}$ & $43.19^{* * * *}$ \\
\hline
\end{tabular}

Note. Scores can range from 1 to 5 . Within rows, means with different subscripts differ at $p<.05$, according to a Newman-Keuls Multiple Comparison test.

$* * * p<.001$. than the avoidant group, but less distressed than the preoccupied group.

Results for the emotional responses were precisely as predicted. Compared to the secure and avoidant groups, preoccupied individuals were much more likely to report that they would feel emotionally distressed in response to the events. In addition, the avoidant group showed the predicted lack of emotion. They reported that they would feel less emotionally distressed and more unemotional than individuals in the secure group. This pattern is consistent with the idea that secure individuals are able to acknowledge distress in response to potentially threatening events.

Behavioral intentions. As shown at the bottom of Table 8, secure and avoidant individuals were less likely than preoccupied individuals to anticipate conflict and to behave in conflictevoking ways, and the avoidant group was less likely than the secure group to respond negatively to their partner.

As predicted, attachment style was related to participants' own expectations of conflict and to their actual behavioral intentions. People who were anxious about being unloved were more likely to anticipate conflict and to behave in ways that were judged as punishing toward their partner and as likely to result in conflict. Relationship satisfaction was also associated with lower expectations of conflict, but did not predict the nature of participants' written behavioral intentions.

Sex differences. To determine if attachment style differences varied for men and women, a series of $2(\operatorname{sex}) \times 3$ (attachment style) MANOVAs were conducted for all outcome variables. Although there were several significant main effects for gender, there were no significant interactions between attachment style and gender (see Footnote 4).

\section{Testing the Mediational Model}

The variables used as indicators of each component of the model and the procedure for testing the mediational model were 
Table 8

Mean Differences on Selected Outcome Measures by Attachment Style: Study 2

\begin{tabular}{lllcc}
\hline \multicolumn{1}{c}{ Outcome variable } & Secure & Avoidant & Preoccupied & $\cdot F(2,126)$ \\
\hline Open-ended explanation ratings & & & & \\
Love/security & $5.99_{\mathrm{a}}$ & 6.11 & $5.64_{\mathrm{b}}$ & $5.08^{* *}$ \\
Responsive/dependable & $4.98_{\mathrm{a}}$ & $5.15_{\mathrm{a}}$ & $4.75_{\mathrm{b}}$ & $4.43^{*}$ \\
Self-worth/reliance & $5.54_{\mathrm{a}}$ & 5.61 & $5.26_{\mathrm{b}}$ & $5.02^{* *}$ \\
Trust & $5.75_{\mathrm{a}}$ & $5.79_{\mathrm{a}}$ & $4.37_{\mathrm{b}}$ & $7.58^{* * *}$ \\
Partner warmth/closeness & $5.03_{\mathrm{a}}$ & 5.08 & $4.73_{\mathrm{b}}$ & $6.75^{* *}$ \\
Minimize negative impact & $6.11_{\mathrm{a}}$ & 6.29 & $5.44_{\mathrm{b}}$ & $5.85^{* *}$ \\
Emotional responses & $3.27_{\mathrm{a}}$ & $2.51_{\mathrm{b}}$ & $3.99_{\mathrm{c}}$ & $10.00^{* * *}$ \\
Distress & 2.83 & $2.24_{\mathrm{a}}$ & $3.20_{\mathrm{b}}$ & $3.72^{*}$ \\
Nervousness & $2.41_{\mathrm{a}}$ & $3.07_{\mathrm{b}}$ & $2.11_{\mathrm{a}}$ & $5.16^{* *}$ \\
Unemotional & & & & \\
Behavioral responses & $3.244_{\mathrm{a}}$ & $2.58_{\mathrm{a}}$ & $3.99_{\mathrm{b}}$ & $8.02^{* * *}$ \\
Self-ratings of conflict & $2.79_{\mathrm{a}}$ & $2.01_{\mathrm{b}}$ & $3.50_{\mathrm{c}}$ & $10.75^{* * *}$ \\
Ratings of behavioral intentions & & & &
\end{tabular}

Note. Scores for the explanation ratings can range from 1 to 9 (recoded from -4 to +4 ); all other scores range from 1 to 7 . Within rows, means with different subscripts differ at $p<.05$, according to a NewmanKeuls Multiple Comparison test.

${ }^{*} p<.05 .^{* *} p<.01{ }^{* * *} p<.001$.

identical to those in Study 1. The only differences in the model were that relationship quality was added as an additional variable that had a direct path to explanation patterns, and correlational paths between relationship quality and the attachmentstyle dimensions were also added.

The hypothesized model was estimated first, resulting in $\chi^{2}(4, N=129)=1.42, p=.84, \mathrm{CFI}=1.0$. Although the model fit was very good, the path linking close-depend to explanation patterns was not significant. Therefore, this path was removed and the model reestimated. All remaining paths were signifcant, $\chi^{2}(5, N=129)=2.64, p=.76, \mathrm{CFI}=1.0$. Parameter estimates for the final model are shown in Figure 3.

As predicted, relationship quality and attachment style both had significant, independent associations with explanation patterns. This finding is consistent with the argument that global models as well as relationship-specific models will contribute to an individual's understanding of events in their relationships. However, consistent with the regression analyses, fear of being unloved was the only attachment dimension that directly predicted explanations. Next, consistent with Study 1, those anxious about being unloved and those who explained their partner's behavior in a negative manner reported greater emotional distress. As predicted, being comfortable with closeness and depending on others was also associated with greater distress. This result is consistent with the finding that secure individuals ( who are highest on these dimensions) were more willing than avoidant individuals (who are lowest on these dimensions) to acknowledge emotional distress. As predicted, there was only an indirect link between relationship quality and emotions, mediated through explanations. This finding suggests that the influ-

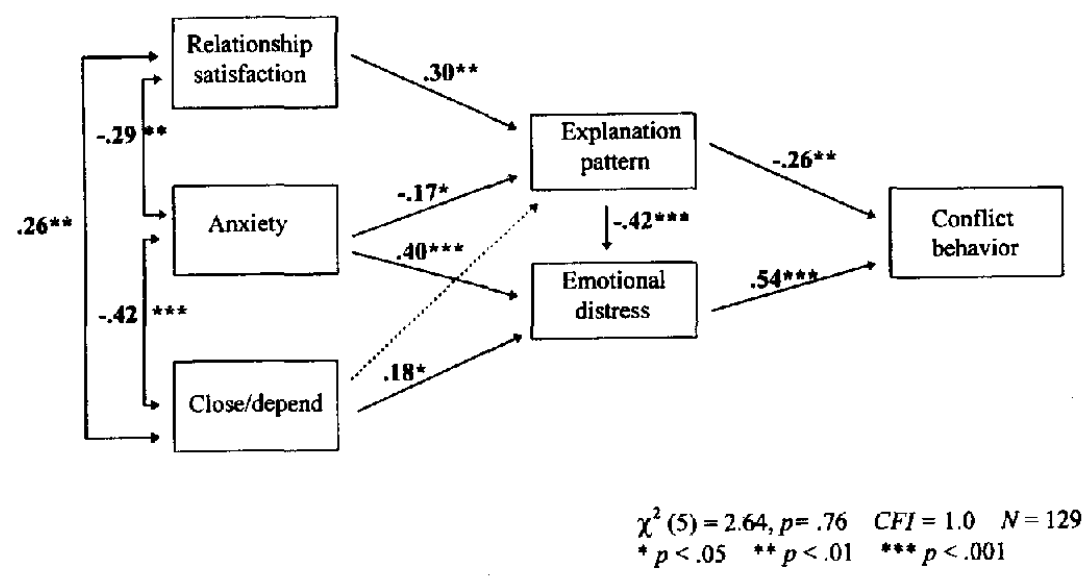

Figure 3. Final parameter estimates and goodness-of-fit statistics for the mediational model in Study 2. Numbers on double-headed arrows are correlation coefficients; numbers on single-headed arrows are standardized regression coefficients. Dashed lines indicate nonsignificant paths that were dropped from the final model. CFI = comparative fit index. 
ence of attachment style on emotional experience will be relatively unaffected by the quality of one's current relationship. This is especially noteworthy given that emotional responses were such a strong predictor of behavioral intentions. Finally, negative explanations and emotional distress resulted in behavioral descriptions that were judged as more punishing and more likely to lead to conflict.

Overall, the mediational model appeared to be a good representation of the underlying relationships among these variables. These results provide further support for the hypothesized underlying processes and indicate that the results of Study 1 were not unique to hypothetical relationships. However, to provide further support for the model, two additional models were run. The first model included direct paths from the two attachmentstyle dimensions to behavioral intentions. Neither path was statistically significant, indicating that any links between attachment style and behavior were mediated through explanations and emotions. The second model included a latent explanation variable made up of the eight attachment-theme dimensions. The results based on this model were virtually identical to those presented for the more simplified model.

\section{General Discussion}

\section{Attachment Style Differences in Explanations and Attributions}

The primary purpose of this research was to test the hypothesis that adults with different attachment styles would explain and interpret events in ways consistent with their beliefs and expectations about themselves and others. Content coding of open-ended explanations provided strong support for this hypothesis. In both studies, preoccupied individuals were likely to construct explanations that offered much more negative views of their partner and more negative interpretations of events. Consistent with participants' expectations, their explanations were more likely to suggest that their relationship was in jeopardy, and that their partner was unresponsive to their needs, not trustworthy, and purposely rejecting closeness. Their explanations also reflected lower self-worth and self-reliance. In contrast, secure adults provided much more positive explanations. Consistent with their optimistic models of self and others, their explanations were more likely to communicate confidence in their relationship and in their partner's love, they were less likely to view their partner's behavior as purposely rejecting closeness, and overall they tended to construe events in ways that minimized their negative impact and limited their importance for broader issues of relationship stability. These patterns were further supported by results on the structured attribution ratings, although the pattern on these measures was stronger in Study 1 than in Study 2.

Although the findings for secure and preoccupied groups were consistent across the two studies, an interesting pattern emerged for the avoidant group. In Study 1, avoidant individuals provided negative explanations similar to those given by preoccupied participants. However, in Study 2 they provided positive explanations that were more similar to those given by secure participants. Another way of conceptualizing this pattern is that, in Study 1, comfort with relationships (closeness and depending) and anxiety about being unloved were both associated with explanation patterns; in Study 2, only the anxiety dimension remained strongly predictive.

There are a number of possible explanations for this pattern. One reason may be that avoidant adults were willing to draw negative conclusions about their relationship in the context of a fictional dating relationship, but were unwilling to do so in the context of their current romantic relationship because such conclusions may be too threatening to the self. On the one hand, avoidants' negative view of human nature and of relationships might have led them to conclude that their partner was selfish and rejecting. On the other hand, drawing such a conclusion would have implied that they were not valued by others, and that they were concerned about such things-both of which would be incompatible with their desire to appear self-confident and self-sufficient. Thus, the avoidant group's positive response pattern in Study 2 may reflect a defensive strategy for dealing with this potential dilemma and for protecting their self-image. This interpretation is consistent with theoretical descriptions of the avoidant style as defensively high in self-esteem and selfreliance (Bartholomew, 1990).

Another possible explanation for this difference is that the two samples may have differed in important ways. In a number of studies (e.g., Collins \& Allard, 1994; Collins \& Read, 1990), it was found that the distribution of attachment styles differs in samples of dating and nondating adults. Recall that in Study 1 only half of the participants were currently dating, whereas all participants in Study 2 were involved in a steady dating relationship. A comparison of the means on the three attachment dimensions indicated that, overall, the sample in Study 1 was less secure; they were less comfortable with closeness, $t(260)=$ $-1.88, p<.10$, less willing to depend on others, $t(260)=-3.01$, $p<.01$, and more concerned about being rejected, $t(260)=$ $3.08, p<.01$.

However, a more specific and important difference may have been in the nature of avoidance in the two samples. Specifically, Bartholomew (1990) has argued that attachment researchers need to distinguish between two types of avoidance. Fearful avoidants avoid getting close to others because they worry about being hurt and rejected. These individuals have negative models of both self and others. Dismissing avoidants avoid close relationships because they desire to be independent and self-sufficient. These individuals have negative models of others but positive models of the self. Because fearfuls are least likely to be involved in steady dating relationships, it is reasonable to assume that the avoidant participants in Study 1 were more likely to have been fearful, and the avoidant participants in Study 2 were more likely to have been dismissing. Although I did not have a measure of the four styles in the current studies, it was possible to examine this issue in an exploratory manner by creating the four styles on the basis of scores on the three attachment dimensions. As noted earlier, the close and depend dimensions are more closely associated with models of others, and the anxiety dimension is more closely associated with models of the self. Therefore, I created four attachment styles by considering each person's profile of scores along the dimensions (close and depend were first averaged to form a single score). High scores were defined as above the midpoint of the scale (i.e., above 3), and low scores were defined as below the midpoint (participants 
who fell at the midpoint were given missing values). For example, a person who had a low score on close-depend and a low score on anxiety was categorized as dismissing, and a person with a low score on close-depend but a high score on anxiety was categorized as fearful. A comparison of the breakdown for the styles in each sample supports the idea that the samples were somewhat different. In Study 1, the sample included 50\% secure, $17 \%$ preoccupied, $20 \%$ fearful, and $12 \%$ dismissing. In Study 2 , the sample included $62 \%$ secure, $14 \%$ preoccupied, $11 \%$ fearful, and $14 \%$ dismissing. As expected, there was a much larger percentage of secure participants in the dating sample. More important, there were half as many fearful avoidants and slightly more dismissing avoidants. I then examined mean differences on all explanation variables across both studies to determine if the negative pattern for avoidants in Study 1 was primarily reflecting the fearful avoidant and not the dismissing avoidant. As expected, in both studies, the fearful avoidants consistently obtained the lowest mean scores on the explanation ratings. Nevertheless, the dismissing group still tended to be more negative than the secure group in Study 1 (but not in Study 2). Unfortunately, I could not run the Study 1 analyses separately for dating and nondating participants because only 5 of the dating participants were categorized as dismissing.

These exploratory analyses provide some support that the two samples differed in their degree of insecurity, and that the negative pattern in Study 1 was being driven primarily by fearful avoidants. However, there was still some evidence that dismissing adults were responding more negatively to the hypothetical relationship than to their real relationship. I am currently following up on these findings by measuring the four attachment styles more carefully and by manipulating real versus fictional relationships in a single study (Collins \& Allard, 1994). Preliminary results indicate that for both real and hypothetical relationships, dismissing avoidants provide explanations that are more similar to secure respondents', and fearful avoidants provide negative explanations and attributions that are more similar to preoccupied adults'. Although additional work is needed, these findings suggest that attachment researchers need to consider the interplay of cognitive and motivational factors when attempting to understand the explanation process. For example, our lab is currently planning studies to examine the hypothesis that the positive explanations provided by dismissing avoidants are the result of a motivated defensive strategy.

One of the assumptions guiding this research is that working models of attachment were activated in memory and used to shape the social perception process. What evidence do I have for this assumption? The strongest evidence was provided by comparing the content of participants' free-response explanations for attachment-relevant and attachment-irrelevant events. Over $50 \%$ of participants in Study 1 and over 30\% of participants in Study 2 spontaneously mentioned as least one of the eight attachment themes in their explanations. Moreover, across all attachment styles, participants were half as likely to mention an attachment theme in response to attachment-irrelevant events. Also, as predicted, individual differences in attachment style were not associated with the content of these explanations. These results are important for two reasons. First, they are consistent with the argument that working models of attachment are functionally specific. That is, they are selectively activated or used in response to relevant environmental stimuli. Second, these findings provide evidence that the link between attachment style and explanations was not simply the result of a general perceptual style or response bias. Indeed, knowledge structures unrelated to attachment seem to have provided a better basis for understanding the attachment-irrelevant events. It is also likely that attachment-relevant models were activated but were not used because they simply provided less plausible explanations. Clearly, not all social events should be interpreted on the basis of attachment-related knowledge structures. Many events are better understood with reference to commonly shared behavioral scripts, person prototypes, sex-role stereotypes, and so on. In the current samples, a review of the explanations suggested that the irrelevant events (e.g., partner was late for a date, forgot birthday, or didn't pay back money) tended to activate stereotypes of the "typical college student," who was seen as high on stress and very low on financial resources.

Another important finding is that, in Study 2, attachment style predicted explanations independent of current relationship quality. This association was important to establish because attachment style consistently covaries with relationship quality, and differences in explanations may have simply reflected differences in the nature and quality of one's current dating relationship. As expected, individuals who had more satisfying relationships were more likely to interpret their partner's behavior in positive ways. However, independent of relationship quality, individuals who were worried about being rejected interpreted their partner's behavior in much more negative ways. Comfort with closeness and depending on others was not related to explanations in this dating sample. Another way to view this pattern is that, even controlling for relationship quality, secure (and dismissing) adults were more optimistic in their explanations, whereas preoccupied (and fearful) adults were more pessimistic. It may be that, for people in relationships, general models about the warmth and dependability of others are less salient than perceptions of the current partner's caring and responsiveness. Thus, concrete models of a specific partner's responsiveness may provide more plausible explanations and may be preferred over more general models about the social world. However, if relationship-specific models are preferred over more general models, why does anxiety about relationships continue to be an important predictor? One reason may be that being comfortable with relationships is more closely associated with models of others, whereas anxiety is more closely linked to negative models of the self (Bartholomew \& Horowitz, 1991; Bowlby, 1982; Bretherton, 1985; Collins \& Read, 1990; Feeney \& Noller, 1990; Hazan \& Shaver, 1987). Individuals are likely to develop fairly specific and concrete models or schemas of particular relationships and particular partners; however, models of the self are not likely to be completely amended or supplanted in the context of any one relationship (Collins \& Read, 1994). As a result, positive or negative models of the self are likely to remain as important structures through which social information is filtered. Individuals who have negative self-images and who are concerned that others will abandon them may find it difficult to completely set aside their doubts in any relationship. Holmes and Rempel (1989) suggested that people 
who are unsure about their partner's commitment will constantly monitor their partner's behavior for signs that indicate lack of caring. They may be waiting for things to go wrong in their relationship and, when faced with a negative partner behavior, will be ready to assume the worst. Preoccupied and fearful adults, who are chronically worried about this issue, may be likely to adopt such a strategy and, as a result, negative images of the self are likely to be chronically active. One important question is whether attachment style interacts with relationship quality and relationship length. For example, perhaps negative working models of self will lose some of their power in long-term relationships that are characterized by high levels of trust and faith. A related issue is the extent to which working models are flexible and open to change (see Collins \& Read, 1994; Scharfe \& Bartholomew, 1994). These are both important topics for future research.

\section{Attachment Style Differences in Emotions and Behavior}

The second goal of this research was to provide an initial test of the multivariate model linking attachment style and explanation processes to emotional response patterns and behavioral intentions. Drawing from a general model proposed by Collins and Read (1994), it was hypothesized that attachment style would be both directly and indirectly related to emotional responses, and that the link between attachment style and behavioral descriptions would be mediated by explanations and emotions.

The pattern of results for emotional responses in both studies was highly consistent with predictions. As expected, preoccupied adults consistently responded to the events with strong negative emotion, whereas secure and avoidant adults reported much lower levels of negative affect. It was also predicted that secure adults would be willing to acknowledge moderate levels of distress, but that avoidant adults would actively deny feeling distress. This pattern was most clearly supported in Study 2. Avoidant adults reported less distress than secure adults, and were more likely to report that they felt unemotional in response to the events.

There are a number of mechanisms that may explain these patterns. First, results from the structural model suggest that attachment style differences in emotional experience are mediated, in part, by variations in the appraisal and interpretation of events. Thus, in the present context, insecure people felt more emotionally distressed partly because they tended to view their partner's behavior as having negative implications for themselves and for their relationship.

Nonetheless, the path model also supported a direct relation between anxiety and emotions, even after controlling for differences in explanation. There are a number of processes that may account for this direct link between anxiety and emotions. One factor that may be important is differences in personal needs or goals that may be characteristic of people with different attachment styles (Collins \& Read, 1994; Shaver, Collins, \& Clark, 1996). For instance, preoccupied individuals are thought to have a strong desire for attention and physical affection. When this need is not met, or when this goal is blocked (Berscheid, 1983 ), such individuals are likely to become distressed, regardless of the explanation for the event. Thus, preoccupied individ- uals may respond negatively to any situation in which their needs or expectations are not met by their partner, even if their partner's behavior was not negatively motivated. This reasoning is consistent with the infant literature that indicates that preoccupied children have a low tolerance for distress and tend to respond with fear and anxiety whenever there is any disruption in their environment (see Kobak \& Sceery, 1988, for further discussion of emotion regulation). A second factor that may explain this link is that adults with different attachment styles have different strategies for regulating and expressing emotion, and these strategies may be automatically evoked whenever working models are activated (Kobak \& Sceery, 1988; Shaver, Collins, \& Clark, 1996). Finally, working models of attachment contain a great deal of emotional content, which may be automatically triggered whenever working models of attachment are activated in memory (Fiske \& Pavelchak, 1986). Additional research is needed to explore these and other factors that may underlie the link between attachment styles and patterns of emotions.

The idea that attachment style has a direct influence on emotions raises the possibility that emotions have a reciprocal influence on explanation processes. A large body of research points to the significant impact that affective experiences have on a variety of cognitive phenomena ( see Bower \& Cohen, 1982; Clark \& Isen, 1982; Forgas, 1994). This association has been incorporated into the general model presented by Collins and Read (1994), which was shown in Figure 1. Unfortunately, in the present context, a structural model that specified reciprocal links between explanations and emotions was attempted, but the model could not be properly estimated (the parameters were "empirically underidentified"; Hayduk, 1987). Nevertheless, there are good theoretical and empirical reasons to believe that emotional responses will shape how an event is subsequently explained. Thus, the reciprocal influence of emotions and explanations remains an important topic for future work. ${ }^{8}$

The importance of explanations and emotions in relationships lays, in part, on their presumed impact on social behavior. Explanations for events and emotional responses to them were both unique predictors of behavioral intentions, despite the fact that these two variables were highly correlated. It is noteworthy that in Study 2, emotional responses were a much stronger predictor of behavioral descriptions than were explanation patterns. This finding suggests that when participants are responding to a hypothetical relationship, they might overestimate the extent to which their behavior would be driven by cognitive

\footnotetext{
${ }^{8}$ Although it was not possible to test a reciprocal link between explanation patterns and emotional responses in the current studies, it was possible to examine an alternative model in which the path between explanations and emotions was reversed. This model was tested and, in both studies, was found to be an equally good fit to the data. Thus, this alternative model cannot be ruled out on statistical grounds. However, as discussed in Footnote 7 , this model is less defensible on conceptual grounds given the procedures used in this study. The results of the current studies are consistent with the idea that negative attributions will contribute to emotional distress, but the results cannot rule out the reverse, nor were they intended to do so. Future studies are planned to focus more specifically on the mutual influence between cognitive and emotional processes.
} 
(i.e., rational) factors rather than by emotional factors (which tend to be viewed as more irrational and uncontrollable). However, replication of this pattern is needed before any conclusions can be drawn about such processes. Finally, as predicted, the influence of attachment style on negative behavioral patterns was mediated through explanations and emotions.

Taken together, these findings support the hypothesized process model that suggests that adults with different attachment styles are predisposed to behave differently in relationships largely because they think and feel differently within themselves. Moreover, they highlight the importance of incorporating both cognitive and emotional processes into models of interpersonal behavior. Biased cognitive processes are likely to set into motion a pattern of emotional and behavioral responses that shape the interpersonal climate and day-to-day functioning of one's relationship. These processes may also contribute to the maintenance and stability of attachment-relevant knowledge structures as people create environments that verify their existing expectations, both positive and negative (Bartholomew, 1993; Collins \& Read, 1994; Swann, 1983).

\section{Conclusions and Caveats}

The application of attachment theory to the study of adult close relationships is still in its earliest stages. Nevertheless, many studies have shown that attachment style is an important predictor of the nature and quality of adult love relationships. Working models are a central feature of this approach, and are presumed to guide how people operate in relationships and how they construe their social world, although the mechanisms through which this occurs have been poorly understood. The present research is the first to directly explore these mechanisms by incorporating attachment style into a model that includes cognitive processes as well as patterns of affect and behavior. These studies provide strong evidence that attachment styles are indeed related to variations in social perception, which has been suggested but not yet demonstrated in the attachment literature. Of course, many other cognitive processes such as person perception, attention, and memory should also be influenced by working models of attachment (Collins \& Read, 1994), and these deserve attention in future research.

This work also has a number of implications for more general research on attributions in close relationships. The vast majority of research in this area has been concerned with demonstrating a reliable association between attribution patterns and relationship quality based on the assumption that negative patterns of attribution contribute to, or maintain, marital distress. Unfortunately, less attention has been paid to studying the mechanisms responsible for variations in attributional patterns. The current study contributes to this effort by exploring one factor that may underlie such patterns--individual differences in social knowledge that partners bring into their relationships. This idea is consistent with recent models of cognition in close relationships, such as Bradbury and Fincham's (1988) contextual model of interpersonal-marital interaction, and Fletcher and Fincham's (1991) related model of explanation processes in close relationships. These models suggest that cognitive processing of relationship information will be shaped by relatively stable distal factors (e.g., personality, chronic mood states, and goals) and by proximal factors present in the immediate social context (e.g., transitory mood states and social norms). The current work suggests that individual differences in working models of attachment may be one important component of the distal context.

This research differs from related work in this area by focusing on the content of open-ended explanations. Because of the considerable time and effort needed to code these materials, one must consider the merits of their use. Perhaps the most important reason for gathering open-ended explanations is that the content of an explanation is vital to understanding the knowledge that was used to construct it (Read \& Collins, 1991). For example, the presence of spontaneous attachment themes provided support for the idea that attachment-relevant knowledge structures were being used to filter and interpret events. This idea could not be tested as clearly with only abstract attribution dimensions. In fact, in Study 2, attachment style and relationship quality both were more strongly associated with the content of the explanations than with the attributional dimensions. Therefore, if one's goal is to understand how explanations are constructed, content coding of explanations will be vital.

Before concluding, several important limitations of the present work should be acknowledged. First, participants were asked to respond to hypothetical partner behaviors on the basis of very restricted information. As a result, one's ability to generalize these findings to explanation processes in the natural course of relationships may be somewhat limited. Fortunately, past research on attributions in relationships has found that results based on hypothetical events are very consistent with those based on actual relationship events (see Baucom et al., 1989; Bradbury \& Fincham, 1990). A second limitation concerns the use of written behavioral descriptions to make inferences about actual interpersonal behavior. Of course, it is difficult to know the extent to which such descriptions accurately reflect behavioral tendencies, and future studies will need to address this issue by observing behavior in laboratory or field settings. Additional limitations are apparent in our measurement of emotional response patterns. These measures were limited not only because I relied on people's predictions about how they would feel, but also because emotional distress was conceptualized in a very general way. In future studies I plan to examine the link between attachment style and emotional responses by using self-report as well as behavioral indicators of emotion, and by studying a wider range of emotions. Finally, although these data were consistent with the hypothesized structural models, these data are correlational and cannot be used to draw conclusions about causality. Although it is not possible to manipulate attachment style, I am currently planning experimental tests of these relationships by priming certain attachment-related beliefs and experiences in the lab. Longitudinal designs would also be useful in continuing research.

In conclusion, the present work provides insight into the mechanisms that may underlie attachment style differences in relationship quality. More generally, it suggests that to fully understand interpersonal functioning in adulthood, close relationship scholars will need to explore the representational models that guide social perception, emotion, and behavior. Attachment theory provides one valuable framework for continuing this effort. 


\section{References}

Ainsworth, M. D., Blehar, M. C., Waters, E, \& Wall, S. (1978). Patterns of attachment: A psychological study of the strange situation. Hillsdale, NJ: Erlbaum.

Aldenderfer, M. S., \& Blashfield, R. K. (1984). Cluster analysis. Beverly Hills, CA: Sage.

Baldwin, M. (1992). Relational schemas and the processing of social information. Psychological Bulletin, 112, 461-484.

Baldwin, M., Fehr, B., Keedian, E., \& Seidel, M. (1993). An exploration of the relational schemata underlying attachment styles: Self-report and lexical decision approaches. Personality and Social Psychology Bulletin, 19, 746-754.

Bargh, J. A. (1984). Automatic and conscious processing of social information. In R. S. Wyer \& T. K. Srull (Eds.), Handbook of social cognition (Vol. 3, pp. 1-44). Hillsdale, NJ: Erlbaum.

Bartholomew, K. (1990). Avoidance of intimacy: An attachment perspective. Journal of Social and Personal Relationships, 7, 147-178.

Bartholomew, K. (1993). From childhood to adult relationships: An attachment perspective. In S. W. Duck (Ed.), Understanding relationship processes: 2. Learning about relationships (pp. 30-62). London: Sage.

Bartholomew, K., \& Horowitz, L. M. (1991). Attachment styles among young adults: A test of a four-category model. Journal of Personality and Social Psychology. 61, 226-244.

Baucom, D. H., Epstein, N., Sayers, S., \& Sher, T. G. (1989). The role of cognition in marital relationships: Definitional, methodological, and conceptual issues. Journal of Consulting and Clinical Psychology, $57,31-38$

Baucom, D. H., \& Lester, G. W. (1986). The usefulness of cognitive restructuring as an adjunct to behavioral marital therapy. Behavior Therapy: 17, 385-403.

Bentler, P. M. (1989). Theory and implementation of EQS: A structural equations program. Los Angeles: BMDP Statistical Software, Inc.

Bentler, P. M., \& Bonett, D. G. (1980). Significance tests and goodness of fit in the analysis of covariance structures. Psychological Bulletin, $88,588-606$.

Berscheid, E. (1983). Emotion. In H. H. Kelley, E. Berscheid, A. Christensen, J. Harvey, T. Huston, G. Levinger, E. McClintock, A. Peplau, \& D. R. Peterson (Eds.), Close relationships (pp. 110-168). San Francisco: Freeman.

Bower, G. H., \& Cohen, P. R. ( 1982). Emotional influences in memory and thinking: Data and theory. In M. S. Clark \& S. T. Fiske (Eds.), Affect and cognition: The 17th Annual Carnegie Symposium on Cognition. Hillsdale, $\mathrm{NJ}$ : Erlbaum.

Bowlby, J. (1973). Attachment and loss: Vol. 2. Separation, anxiety, and anger. New York: Basic Books.

Bowlby, J. (1980). Attachment and loss: Vol. 3. Loss. New York: Basic Books.

Bowlby, J. (1982). Attachment and loss: Vol. 1. Attachment. New York: Basic Books. (Original work published 1969)

Bradbury, T. N., \& Fincham, F. D. (1987). Affect and cognition in close relationships: Towards an integrative model. Cognition and Emotion, 1, 59-87.

Bradbury, T. N., \& Fincham, F. D. (1988). Individual difference variables in close relationships: A contextual model of marriage as an integrative framework. Journal of Personality and Social Psychology, $54,713-721$.

Bradbury, T. N., \& Fincham, F. D. (1990). Attributions in marriage: Review and critique. Psychological Bulletin, 107, 3-33.

Brennan, K. A., \& Shaver, P. R. (1992). Attachment styles and the "Big Five" personality traits: Their connections with each other and with romantic outcomes. Personality and Social Psychology Bulletin, 18, 536-545.
Brennan, K. A., \& Shaver, P. R. ( 1995). Dimensions of adult attachment, affect regulation, and romantic relationship functioning. Personality and Social Psychology Bulletin, 21, 267-283.

Bretherton, I. (1985). Attachment theory: Retrospect and prospect. Monographs of the Society for Research in Child Development, 50, 335.

Bugental, D. B., Blue, J., Cortez, V., \& Fleck, K. (1993). Social cognitions as organizers of autonomic and affective responses to social challenge. Journal of Personality and Social Psychology, 64, 94-103.

Camper, P. M., Jacobson, N. S., Holzworth-Munroe, A., \& Schmaling, K. B. (1988). Causal attributions for interactional behaviors in married couples. Cognitive Theory and Research, 12, 195-209.

Carnelley, K., \& Janoff-Bulman, R. (1992). Optimism about love relationships: General vs. specific lessons from one's personal experiences. Journal of Social and Personal Relationships, 9, 5-20.

Clark, M. S., \& Isen, A. M. (1982). Toward understanding the relationship between feeling states and social behavior. In A. Hastorf \& A. Isen (Eds.), Cognitive social psychology (pp. 73-108). New York: Elsevier North-Holland.

Collins, N. L., \& Allard, L. (1994). Attachment style differences in attributions, emotions, and behavior. Unpublished manuscript, State University of New York at Buffalo.

Collins, N. L., \& Read, S. J. (1990). Adult attachment, working models, and relationship quality in dating couples. Journal of Personality and Social Psychology, 58, 644-663.

Collins, N. L., \& Read, S. J. ( 1994). Cognitive representations of adult attachment: The structure and function of working models. In K. Bartholomew \& D. Perlman (Eds.), Advances in personal relationships: Vol. 5. Attachment processes in adulthood (pp. 53-90). London: Jessica-Kingsley.

Doherty, W. J. (1982). Attribution style and negative problem solving in marriage. Family Relations, 31, 201-205.

Epstein, N., Pretzer, J. L., \& Fleming, B. (1987). The role of cognitive appraisal in self-reports of marital communication. Behavior Therapy, 18, 51-69.

Feeney, B. C., \& Kirkpatrick, L. A. ( 1996). The effects of adult attachment and presence of romantic partners on physiological responses to stress. Journal of Personality and Social Psychology, 70, 255-270.

Feeney, J. A., \& Noller, P. (1990). Attachment styles as a predictor of adult romantic relationships. Journal of Personality and Social Psychology, 58, 281-291.

Feeney, J. A., \& Noller, P. (1991). Attachment style and verbal descriptions of romantic partners. Journal of Social and Personal Relationships, 8, 187-215.

Feeney, J. A., Noller, P., \& Callan, V. J. (1994) . Attachment style, communication, and satisfaction in the early years of marriage. In K. Bartholomew \& D. Perlman (Eds.), Advances in personal relationships. Vol. 5. Attachment processes in adulthood (pp. 269-308). London: Jessica-Kingsley.

Feeney, J. A., Noller, P., \& Hanrahan, M. (1994). Assessing adult attachment. In M. B. Sperling \& W. H. Berman (Eds.), Attachment in adults: Clinical and developmental perspectives (pp. 128-152). New York: Guilford Press.

Fincham, F. D. (1985). Attributions in close relationships. In J. H. Harvey \& G. Weary (Eds.), Attribution: Basic issues and applications (pp. 203-234). New York: Academic Press.

Fincham, F. D., Beach, S. R., \& Nelson, G. (1987). Attribution processes in distressed and nondistressed couples: 3. Causal and responsibility attributions for spouse behavior. Cognitive Therapy and Research, 11, 71-86.

Fincham, F. D., \& Bradbury, T. N. (1987). The impact of attributions in marriage: A longitudinal analysis. Journal of Personality and Social Psychology, 53, 510-517.

Fincham, F. D., \& Bradbury, T. N. (1988). The impact of attributions 
in marriage: An experimental analysis. Journal of Social and Clinical Psychology, 7, 122-130.

Fincham, F. D., \& Bradbury, T. N. (1989). The impact of attributions in marriage: An individual difference analysis. Journal of Social and Personal Relationships, 6, 69-85.

Fincham, F. D., \& O'Leary, K. D. (1983). Causal inferences for spouse behavior in maritally distressed and nondistressed couples. Journal of Social and Clinical Psychology, 1, 42-57.

Fiske, S. T., \& Pavelchak, M. A. (1986). Category-based versus piecemeal-based affective responses: Developments in schema-triggered affect. In R. M. Sorrentino \& E. T. Higgins (Eds.), Handbook of motivation and cognition: Foundations of social behavior (pp. 167-203). New York: Guilford Press.

Fiske, S. T, \& Taylor, S. E. (1991). Social cognition. New York: McGraw-Hill.

Fletcher, G. J. O., \& Fincham, F. D. (1991). Cognition in close relationships. Hillsdale, NJ: Erlbaum.

Fletcher, G. J. O., Fincham. F. D., Cramer, L., \& Heron, N. (1987). The role of attributions in the development of dating relationships. Journal of Personality and Social Psychology, 53, 481-489.

Fletcher, G. J. O., \& Fitness, J. (1990). Occurrent social cognition in close relationship interactions: The role of proximal and distal variables. Journal of Personality and Social Psychology, 59, 464-474.

Fletcher, G. J. O., \& Fitness, J. (1993). Knowledge structures and explanations in intimate relationships. In S. W. Duck (Ed), Understanding relationship processes: 2 . Learning about relationships (pp. 121-143). London: Sage.

Forgas, J. P. (1994). Sad and guilty? Affective influences on the explanation of conflict in close relationships. Journal of Personality and Social Psychology, 66, 56-68.

Griffin, D. W., \& Bartholomew, K. (1994). The metaphysics of measurement: The case of adult attachment. In K. Bartholomew \& D. Perlman (Eds.), Advances in personal relationships: Vol. 5. Altachment processes in adulthood (pp. 17-52). London: Jessica-Kingsley.

Hayduk, L. (1987). Structural equation modeling with LISREL: Essentials and advances. Baltimore: The Johns Hopkins University Press.

Hazan, C., \& Shaver, P. (1987). Romantic love conceptualized as an attachment process. Journal of Personality and Social Psychology, 52, 511-524.

Hazan, C., \& Shaver, P. R. (1993). Attachment as an organizational framework for research on close relationships. Psychological Inquiry, 5, 1-22.

Holmes, J. G., \& Rempel, J. K. (1989). Trust in close relationships. In C. Hendrick (Ed.), Review of personality and social psychology: Vol. 10. Close relationships (pp. 187-220). London: Sage.

Holtzworth-Munroe, A., \& Jacobson, N. S. ( 1985). Causal attributions of married couples: When do they search for causes? What do they conclude when they do? Journal of Personality and Social Psychology, $48,1398-1412$.

Holtzworth-Munroe, A., \& Jacobson, N. S. (1988). Toward a methodology for coding spontaneous causal attribution: Preliminary results with married couples. Journal of Social and Clinical Psychology, 7, 101-112.

Kirkpatrick, L. A., \& Davis, K. E. (1994). Attachment style, gender, and relationship stability: A longitudinal analysis. Journal of Personality and Social Psychology, 66, 502-512.

Kobak, R. R., \& Hazan, C. (1991). Attachment in marriage: Effects of security and accuracy of working models. Journal of Personality and Social Psychology, 60, 861-869.

Kobak, R. R., \& Sceery, A. (1988). Attachment in late adolescence: Working models, affect regulation, and perception of self and others. Child Development, 59, 135-146.
Lazarus, R. S., \& Folkman, S. (1984). Stress, appraisal, and coping. New York: Springer.

Levy, M. B., \& Davis, K. B. (1988). Lovestyles and attachment styles compared: Their relations to each other and to various relationship characteristics. Journal of Social and Personal Relationships, 5, 439471.

Locke, H., \& Wallace, K. (1959). Short marital adjustment and prediction tests: Their reliability and validity. Marriage and Family Living, 21, 251-255.

Main, M., Kaplan, N., \& Cassidy, J. (1985). Security in infancy, childhood, and adulthood: A move to the level of representation. Monographs of the Society for Research in Child Development, 50, 66-104.

Margolin, G., \& Weiss, R. L. (1978). Comparative evaluation of therapeutic components associated with behavioral marital treatments. Journal of Consulting and Clinical Psychology, 46, 1476-1486.

Markus, H., \& Wurf, E. (1987). The dynamic self-concept: A social psychological perspective. Annual review of psychology (Vol. 38, pp. 299-337). Palo Alto, CA: Annual Reviews, Inc.

Markus, H., \& Zajonc, R. B. (1985). The cognitive perspective in social psychology. In G. Lindzey \& E. Aronson (Eds.), The handbook of social psychology, 3rd edition (Vol. 1, pp. 137-230). New York: Random House.

Mikulincer, M. (1995). Attachment style and the mental representation of the self. Journal of Personality and Social Psychology. 69, 12031215.

Passer, M. W., Kelley, H. H., \& Michela, J. L. (1978). Multidimensional scaling of the causes for negative interpersonal behavior. Journal of Personality and Social Psychology, 36, 951-962.

Read, S. J., \& Collins, N. L. (1991). Accounting for relationships: A knowledge structure approach. In J. Harvey, T. Orbuch, \& A. Weber (Eds.), Attributions, accounts, and close relationships (pp. 116-143). New York: Springer-Verlag.

Roseman, I. J. (1984). Cognitive determinants of emotion: A structural theory. In P. Shaver (Ed.), Review of personality and social psychology (Vol. 5, pp. 11-36). Beverly Hills, CA: Sage.

Rothbard, J., \& Shaver, P. R. (1994). Continuity of attachment across the lifespan. In M. B. Sperling \& W. H. Berman (Eds.), Attachment in adults: Clinical and developmental perspectives ( $\mathrm{pp} .31-71$ ). New York: Guilford Press.

Scharfe, E., \& Bartholomew, K. (1994). Reliability and stability of adult attachment patterns. Personal Relationships, 1, 23-43.

Senchak, M., \& Leonard, K. (1992). Attachment styles and marital adjustment among newlywed couples. Journal of Social and Personal Relationships, 9, 51-64.

Shaver, P. R., Collins, N. L., \& Clark, C. (1996). Attachment styles and internal working models of self and relationship partners. In G. J.O. Fletcher \& J. Fitness (Eds.), Knowledge structures in close relationships: A social psychological approach (pp. 25-61). Hillsdale, NJ: Erlbaum.

Shaver, P. R., \& Hazan, C. (1993). Adult romantic attachment: Theory and evidence. In D. Perlman \& W. Jones (Eds.), Advances in personal relationships: A research annual (Vol. 4, pp. 29-70). London: Jessica Kingsley Publishers.

Simpson, J. A. (1990). The influence of attachment styles on romantic relationships. Journal of Personality and Social Psychology. 59, 971 980.

Simpson, J., Rholes, W., \& Nelligan, J. (1992). Support seeking and support giving within couples in an anxiety provoking situation: The role of attachment styles. Journal of Personality and Social Psychology, 62, 434-446.

Spanier, G. B. (1976). Measuring dyadic adjustment: New scales for assessing the quality of marriage and similar dyads. Journal of Marriage and the Family, 38, 15-28. 
Sroufe, L. A., \& Waters, E. (1977). Attachment as an organizational construct. Child Development, 48, 1184-1199.

Swann, W. B. ( 1983). Self-verification: Bringing social reality into har* mony with the self. In J. Suls \& A. G. Greenwald (Eds.), Psychological perspectives on the self: Vol. 2 (pp. 33-66). Hillsdale, $\mathrm{NJ}$ : Erlbaum

Weiner, B. (1982). The emotional consequences of causal attributions. In M. S. Clark \& S. J. Fiske (Eds.), Affect and cognition: The Seven- teenth Annual Carnegie Symposium on Cognition. Hillsdale, NJ: Erlbaum.

Weiner, B. (1985). An attributional theory of achievement motivation and emotion. Psychological Review, 92, 548-573.

Received February 13, 1995

Revision received February 23, 1996

Accepted February 27, 1996

\title{
Call for Papers
}

Review of General Psychology, the official journal of APA Division 1, will begin publication in March 1997. The journal seeks to publish innovative theoretical, conceptual, or methodological articles that cross-cut the traditional subdisciplines of psychology. Review of General Psychology contains articles that advance theory, evaluate and integrate research literatures, provide a new historical analysis, or discuss new methodological developments in psychology as a whole. Of special interest are papers that bridge gaps between subdisciplines in psychology as well as related fields or that focus on topics that transcend traditional subdisciplinary boundaries. Manuscripts that might be submitted to Psychological Bulletin or Psychological Review are of particular interest to Review of General Psychology when they provide a provocative challenge to customary or prevailing views. Indeed, intellectual risk taking is encouraged. Some of the most exciting work in psychology is at the edges of subdisciplines, and traditional journals accommodate such articles only with difficulty; Review of General Psychology invites these kinds of manuscripts. Papers devoted primarily to reporting new empirical findings are generally not appropriate for this journal.

The target audience for Review of General Psychology consists of those psychologists who appreciate both generalism and specialization and who share a vision of psychology as a unified discipline with common theoretical, methodological, and substantive values. Authors are encouraged to write their manuscripts from the perspective of more than one subdiscipline and to review literature that spans at least two subdisciplines in order to attract a broad readership. In this era of heightened specialization, Review of General Psychology is committed to the goal of publishing articles from which all psychologists and other social and behavioral scientists can benefit, regardless of subfield or expertise.

Authors should prepare manuscripts according to the Publication Manual of the American Psychological Association (4th ed.). All manuscripts must include an abstract containing a maximum of 960 characters and spaces (approximately 120 words). Manuscripts that exceed 50 pages in length (not including references, tables, and figures) generally will be returned without review.

In addition to addresses and telephone numbers, authors should include electronic addresses and fax numbers, if available. Submit manuscripts (five copies) to

\author{
Peter Salovey, Editor \\ Review of General Psychology \\ Department of Psychology \\ Yale University \\ P.O. Box 208205 \\ New Haven, CT 06520-8205
}

Review of General Psychology will be published quarterly by the Educational Publishing Foundation, a subsidiary imprint of the American Psychological Association devoted to the quality publication of specialty journals. 